http://jmscr.igmpublication.org/home/ ISSN (e)-2347-176x ISSN (p) 2455-0450 crossref DOI: https://dx.doi.org/10.18535/jmscr/v8i10.15

\author{
Journal Of Medical Science And Clinical Research

$\underline{\text { Research Article }}$

\title{
An analysis of Histopathology and Expression of GFAP in Glial Tumors
}

\author{
Authors \\ Dr Surekha Bantumilli MD ${ }^{1 *}$, Dr Megala Chandrasekar ${ }^{2}$, Dr Saranya Venkatesh ${ }^{3}$
}

Coimbatore Medical College, Department of Pathology, Avinashi Rd, Peelamedu, Civil Aerodrome Post, Coimbatore, Tamil Nadu 641018, India.

*Corresponding Author

Dr Surekha Bantumilli MD

\begin{abstract}
Introduction: Glial tumours are the most common primary tumours of brain with survival rate depending on the grade of tumour. Neurological examination, imaging and histopathological examination helps in diagnosis. Though histopathological analysis is gold standard, immunohistochemical studies aids in confirmation of diagnosis. Expression of GFAP decreases with increase the grade of glial tumours.

GFAP helps in differentiating different types of glial tumours on one hand and glial and non-glial tumours on other hand.

Aims: To study the histomorphological patterns of glial tumours using Haematoxylin and Eosin stained sections for initial diagnosis and to evaluate expression of GFAP in glial tumours and correlate GFAP expression with tumour grading.

Methods: This is a prospective study undertaken for a period of one year. A total sample of 30 cases of glial tumours were studied by histopathological and immunohistochemical technique during period of July 2014 to July 2015.

Results: In present study GFAP expression was positive in $87 \%$ cases. The mean age of incidence of glial tumour in present study is 40 years. The overall male to female ratio observed was 1.3:1. In current study there was inverse correlation with grade of glioma and GFAP expression with low grade tumours showing intense GFAP staining and higher-grade tumour showing less expression.

Conclusion: Thus GFAP expression can be applied as surrogate marker in assessing the grade of the tumour. GFAP can also be used to indirectly assess the grade of tumour and helps in management of glial tumour.
\end{abstract}

Keywords: Glioma, GFAP.

\section{Introduction}

Gliomas constitute largest and most heterogenous group of central nervous system which arises from the supportive tissues of brain. Glioma includes all glial tumours in general (astrocytoma, oligodendroglioma, ependymoma, and glioblastoma and its variants) ${ }^{1}$. Gliomas affect all age groups but are common in adults. Incidence varies with gender and age. In adults, most common tumours are metastases, glioblastoma and meningioma. In children ependymoma, medulloblastoma and pilocytic astrocytoma are more common. ${ }^{1}$ 
Tumours are classified benign and malignant based on histological features. Tumours have certain distinct radiological features and specific anatomic sites. Diagnosis depends on the neuroradiological assessment which is an aid for gross examination. Thus diagnosis of glial tumors of central Nervous System (CNS) relies on a combination of clinical history, imaging studies and histopathological tests ${ }^{4}$ Pathological examination includes cytological preparation, histopathological examination, using frozen section and immunohistochemical study, cytogenetic analysis and electron microscopic study. ${ }^{4,5,6}$,

Immunohistochemistry is now used for diagnosis and confirmation of CNS tumours. Most used glial marker is GFAP which high lights tumour grade and helps in differentiating glial and nonglial tumours. Recurrence of tumour often show higher grade lesion and poor prognosis. Now tumour initiating stem cells which help in tumour growth are under study so that they may be used for targeted therapy. ${ }^{2,3}$ Treatment for brain gliomas depends on the location, the cell type, and the grade of malignancy. Often, treatment is a combined approach using surgery, radiation therapy, and chemotherapy. The radiation therapy is in the form of external beam radiation or the stereotactic approach using radio surgery. Spinal cord tumors can be treated by surgery and radiation. Temozolomide, a chemotherapeutic drug, is able to cross the blood-brain barrier effectively and is currently being used in therapy for high-grade tumors. ${ }^{8}$

\section{Objectives}

1. To study the histomorphological patterns of glial tumours using haematoxylin and eosin stained sections for initial diagnosis

2. To evaluate expression of GFAP in glial tumours.

3. To correlate GFAP expression with tumour grading.

4. To correlate results with patient age ,sex, location and grade of tumour.

\section{Materials and Methods}

The study is conducted in our Department of Pathology. This is both prospective and retrospective study conducted in the department of pathology during period of July 2014 to July 2015. Ethical clearance was obtained. A total sample of 30 cases of glial tumours were studied by histopathological and immunohistochemical technique during period of July 2014 to July 2015

Inclusion Criteria: Specimen from all age groups with suspected glial tumours.

Exclusion Criteria: Inadequate specimen and Specimen not sent in formalin

\section{Data Collection:}

For the period of july2014 to July 2015, excision biopsies of neuropathological specimens sent to the Department of Pathology were included. Thorough history was taken, and findings were recorded on predesigned and pretested proforma (Annexure I).

\section{Technique}

The formalin fixed specimens received in the pathology department were grossed and tumorbits were submitted for processing. After processing, thickness of about 3-4 microns were cut from the paraffin block followed by staining of slides by routine Haematoxylin and Eosin stain. Then slides are studied by light microscopy. Histopathological and immunohistochemical evaluation was done.

\section{Immunohistochemical Evaluation}

The marker of the present study is glial fibrillary acidic protein (GFAP). The slides were stained by a procedure explained above.

For evaluation of GFAP expression, a semiquantitative scoring is used. It includes proportional score and intensity score. Proportional score is the number of cells staining positive. The number of positive cells was given as 0 -none, 1 for $<5 \%, 2$ for $5-25 \%, 3$ for $25-75 \%$, 4 for $75-100 \%$. Intensity staining is given score 0 to $3+$.Summation of proportional score and intensity score gives the total score according to Catherine L. Nutt et al. ${ }^{96}$ A total score of $0-2$ is considered negative, whereas $>3$ is considered positive. 


\section{Statistical Analysis}

The correlation between GFAP expression and grading and other clinicopathological variable were studied by $\mathrm{X}^{2}$ - test or Fisher Freeman Holton's test and Fisher's exact test, if needed. The results were considered statistically significant if the $\mathrm{P}$ value is $<0.05$.

\section{Results and Observation}

A total sample of 30 cases of glial tumours were analysed during the period of study. Histopathological and immunohistochemical evaluation was done.

In the present study,

1. Majority of tumours were astrocytomas accounting for $73 \%$ followed by ependymoma which accounts for $13 \%$ and oligodendroglioma accounting for $10 \%$ and oligoastrocytoma was $3 \%$ forming the least.

2. Male to female ratio is $1.3: 1$ indicating glial tumours are more common in male gender.

3. Majority of tumours were originating from supratentorium which includes cerebrum accounting for $73 \%$, Infratentorium (cerebellum and brain stem) accounting for $27 \%$.

4. Most adult tumours are supratentorial in origin, while all pediatric tumours were infratentorial in origin.

5. Out of 30 studied cases GFAP expression was positive in 26 cases which accounts for $87 \%$.

6. Immunohistochemically GFAP was expressed in 19 cases $(73 \%)$ of astrocytoma, all 4 cases $(15 \%)$ of ependymoma, 2 cases $(8 \%)$ of oligodendroglioma, 1 case $(4 \%)$ of oligo astrocytoma. No expression was seen in 3 cases of astrocytoma and 1 case of anaplastic oligodendroglioma.

7. GFAP was expressed in 14 male cases which accounts for $54 \%$ and 12 female cases accounting to $46 \%$. No significant relation was present between sex and GFAP expression.

8. 19 cases out of 22 supratentorial tumours were positive for GFAP and 7 out of 8 infratentorial tumours were positive for GFAP.

9. GFAP positivity is seen in all 2 cases of pilocytic astrocytoma, 1 case of subependymoma among grade I tumours.

10. Among grade II tumours 5 cases of diffuse astrocytoma , 2 cases of ependymoma and one case of oligodendroglioma were positive.

11. Among grade III tumours 2 cases of astrocytoma, one case of anaplastic oligodendroglioma, anaplastic ependymoma and oligoastrocytoma were positive.

12. Among grade IV tumours all 10 cases of GBM were positive for GFAP.

$13.12 \%$ of grade I tumours, $31 \%$ of grade II tumours, $19 \%$ of grade III tumours and $38 \%$ of grade IV tumours were expressing GFAP positivity.

14. 7 out 8 recurrence positive cases were positive for GFAP expression which accounts for $27 \%$.

15. Among 11 cases in score 4, 27\% cases are grade $1,55 \%$ cases had grade II and and $18 \%$ cases are grade IV.

16. Out of 9 cases in score 3, 22\% cases are grade II and III each, $56 \%$ cases are grade IV.

17. Among 6 cases of score 2, $50 \%$ cases are grade III and IV each.

18. $100 \%$ (3) cases grade 1 tumours had score 4 ,

19. Grade II $75 \%$ cases (6/8) had score 4, remaining two cases had score 3.

20. Grade III none of cases showed score 4, $40 \%$ cases had score 3 and $60 \%$ cases showed score 2 . grade IV $30 \%$ cases had score 2, 50\%cases had score 3 and only $20 \%$ cases had score 4 . Thus there is 
significant inverse relation between proportional score and grade of glioma.

21.14 cases had intensity score $3+, 8$ cases had score $2+$, and 4 cases had score $1+$. As grade increases the intensity core decreases.
22. $3 \backslash 3$ grade I, 7/8 grade II, 0/5 grade III, 4/10 grade IV tumours had score 6-7 suggesting the inverse relation between the tumour grade and total score of GFAP expression.

Table 1: Proportional Score

\begin{tabular}{|l|c|c|c|c|}
\hline No. of positive cells & $<5 \%$ & $5-25 \%$ & $25-75 \%$ & $75-100 \%$ \\
\hline score & 1 & 2 & 3 & 4 \\
\hline
\end{tabular}

Table 2: Intensity Score

\begin{tabular}{|l|l|}
\hline $\mathbf{0}$ & For immunostaining of perikaryons and processes is absent \\
\hline+ & $\begin{array}{l}\text { For cells staining of sparse tumour cell that could not be distinguished from reactive } \\
\text { astrocytes i.e. } \mathbf{1 0 \%}\end{array}$ \\
\hline++ & For cells staining of sparse tumour cell within the tumour i.e. $>\mathbf{1 0 \%}$ \\
\hline+++ & For strong widespread staining of tumour cells \\
\hline
\end{tabular}

Table 3: Total Score

Proportional Score + Intensity Score

\begin{tabular}{|l|c|c|c|c|}
\hline TOTAL SCORE & $0-2$ & $3-4$ & 5 & $6-7$ \\
\hline
\end{tabular}

A total score of $0-2$ is considered negative, whereas $>3$ is considered positive.

Table 4: Distribution of GFAP Positive Tumours by Grade

\begin{tabular}{lccccc}
\hline \multicolumn{1}{c}{ GRADE } & ASTROCYTOMA & OLIGIDENDROGLIOMA & EPENDYMOMA & OLIGOASTROCYTOMA & TOTAL \\
\hline GRADE I & 2 & 0 & 1 & 0 & 3 \\
GRADE II & 5 & 1 & 2 & 0 & 8 \\
GRADE III & 2 & 1 & 1 & 0 & 0 \\
GRADE IV & 10 & 0 & 4 & 1 & 1 \\
\hline
\end{tabular}

In the present study GFAP positivity is seen in all 2 cases of pilocytic astrocytoma, 1 case of subependymoma among grade I tumours. Among grade II tumours 5 cases of diffuse astrocytoma, 2 cases of ependymoma and one case of oligodendroglioma were positive. Among grade
III tumours 2 cases of astrocytoma, one case of anaplastic oligodendroglioma, anaplastic ependymoma and oligoastrocytoma were positive. Among grade IV tumours all 10 cases of GBM were positive for GFAP. 


\section{JMSCR Vol||08||Issue||10||Page 94-115||October}

Table 5: Relationship between GFAP Proportional Score and Grade of Glioma

\begin{tabular}{lcccccc}
\multicolumn{7}{c}{ Relationship between GFAP Proportional Score (PS) and the Grade of Glioma } \\
\hline & \multicolumn{7}{c}{ Positivity } & & \\
GRADE & $\mathbf{5 \%}$ & $\mathbf{5 - 2 5 \%}$ & $\mathbf{2 5} \mathbf{- 7 5 \%}$ & $\mathbf{7 5 - \mathbf { 1 0 0 \% }}$ & Total & $(\%)$ \\
\hline & $\mathbf{1}$ & $\mathbf{2}$ & $\mathbf{3}$ & $\mathbf{4}$ & & \\
\hline GRADE I & 0 & 0 & 0 & 3 & 3 & $12 \%$ \\
GRADE II & 0 & 0 & 2 & 6 & 8 & $31 \%$ \\
GRADE III & 0 & 3 & 2 & 0 & 5 & $19 \%$ \\
GRADE IV & 0 & 3 & 5 & 2 & 10 & $38 \%$ \\
\hline Total & 0 & 6 & 9 & 11 & 26 & \\
\hline \hline
\end{tabular}

Among 11 cases in score 4, 27\% cases are grade $1,55 \%$ cases had grade II and $18 \%$ cases are grade IV. Out of 9 cases in score 3, 22\% cases are grade II and III each, $56 \%$ cases are grade IV. Among 6 cases of score 2, 50\% cases are grade III and IV each.

In the our study $100 \%$ (3) cases grade 1 tumours had score 4, among grade II $75 \%$ cases (6/8) had score 4, remaining two cases had score 3. Among grade III none of cases showed score $4,40 \%$ cases had score 3 and $60 \%$ cases showed score 2 . Among grade IV $30 \%$ cases had score 2, $50 \%$ cases had score 3 and only $20 \%$ cases had score 4 . Thus there is significant inverse relation between proportional score and grade of glioma.

Table 6: Relationship between Intensity Score and Grade of Glioma

\section{Relationship between GFAP Intensity Score and the Grade of Glioma}

\begin{tabular}{cccccc}
\hline & \multicolumn{5}{c}{ Intensity Score } \\
\cline { 2 - 6 } GRADE & $\mathbf{0}$ & $\mathbf{1 +}$ & $\mathbf{2 +}$ & $\mathbf{3 +}$ & Total \\
\hline GRADE I & 0 & 0 & 0 & 3 & 3 \\
GRADE II & 0 & 0 & 1 & 7 & 8 \\
GRADE III & 0 & 2 & 3 & 0 & 5 \\
GRADE IV & 0 & 2 & 4 & 4 & 10 \\
\hline Total & 0 & 4 & 8 & 14 & 26 \\
\hline \hline
\end{tabular}

In the present study 14 cases had intensity score $3+, 8$ cases had score $2+$, and 4 cases had score $1+$. As grade increases the intensity core decreases.

Table 7: Relation between Total Score and Grade of Glioma

\begin{tabular}{|c|c|c|c|c|c|c|}
\hline \multicolumn{7}{|c|}{ Relationship between GFAP Total score and the grade of Glioma } \\
\hline \multirow[b]{2}{*}{ GRADE } & \multicolumn{4}{|c|}{ Total Scores } & \multirow[b]{2}{*}{ Total } & \multirow[b]{2}{*}{$(\%)$} \\
\hline & $0-2$ & $3-4$ & 5 & $6-7$ & & \\
\hline GRADE I & 0 & 0 & 0 & 3 & 3 & $10 \%$ \\
\hline GRADE II & 2 & 0 & 1 & 7 & 10 & $33 \%$ \\
\hline GRADE III & 2 & 5 & 0 & 0 & 7 & $23 \%$ \\
\hline GRADE IV & 0 & 5 & 1 & 4 & 10 & $33 \%$ \\
\hline Total & 4 & 10 & 2 & 14 & 30 & $100 \%$ \\
\hline
\end{tabular}

In the present study all 313 grade I, $7 / 8$ grade II , $0 / 5$ grade III ,4/10 grade IV tumours had score 6-
7 suggesting the inverse relation between the tumour grade and total score of GFAP expression. 
Chart 1: Distribution of Gliomas in Present Study

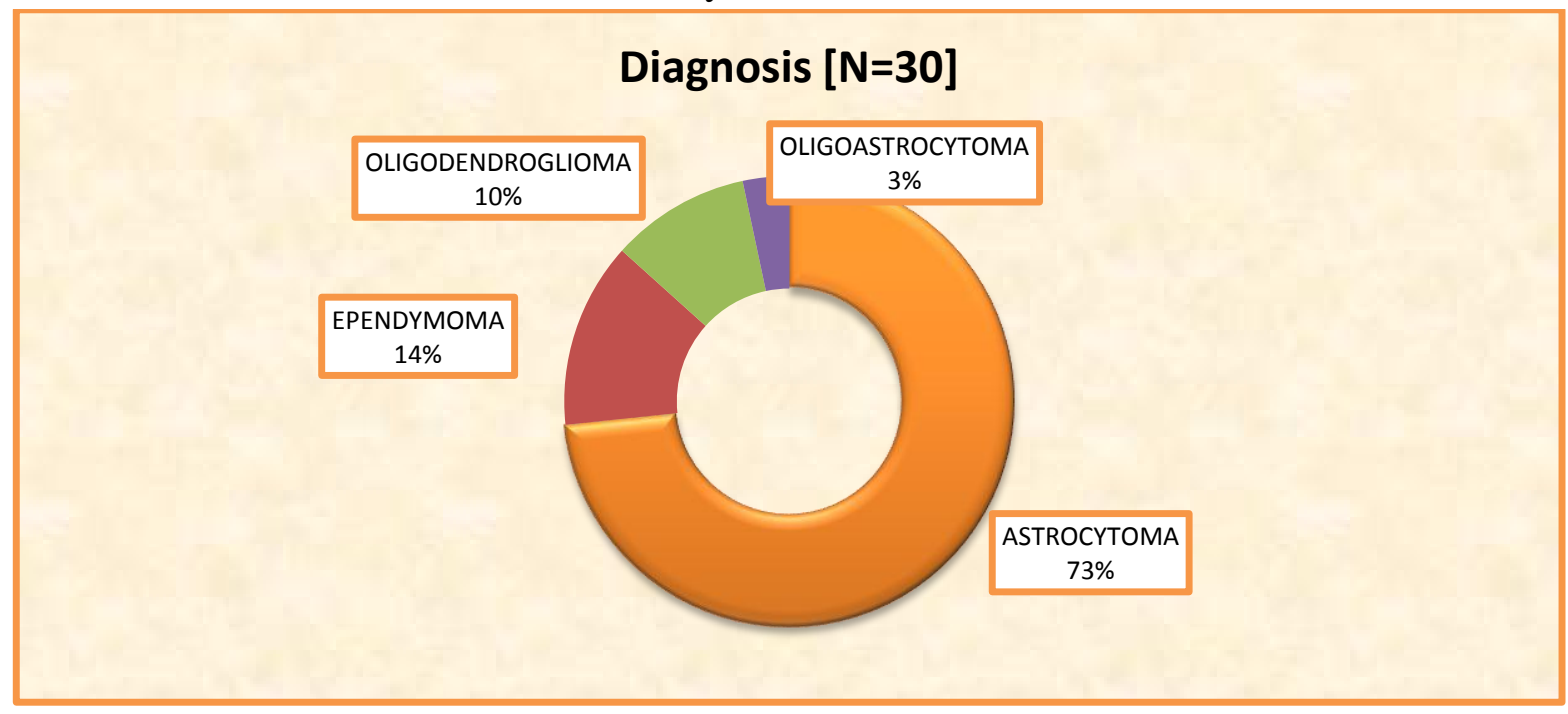

Chart 2: Age Wise Distribution of Glial Tumours

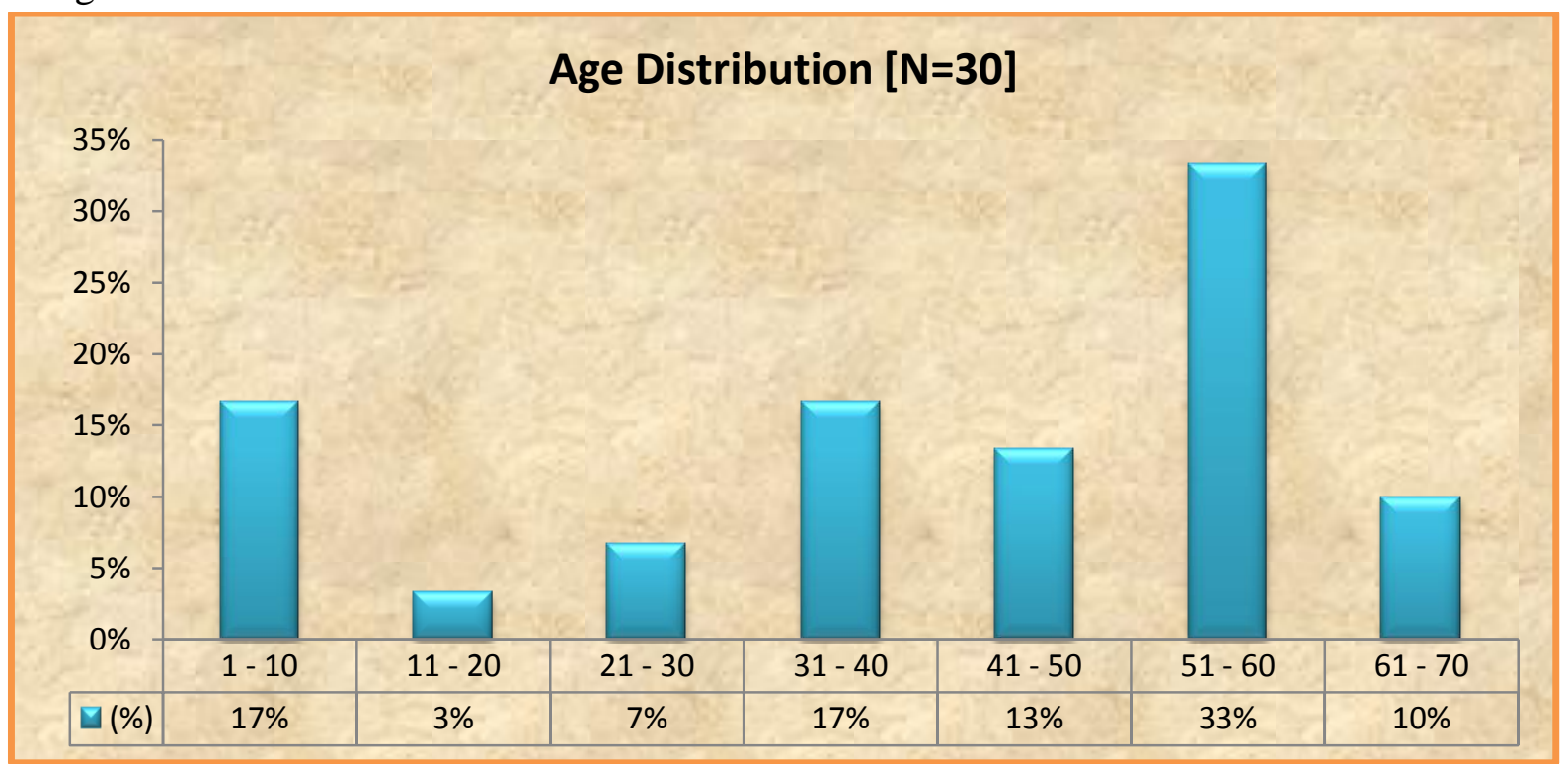

Chart 3: GFAP Expression in Present Study

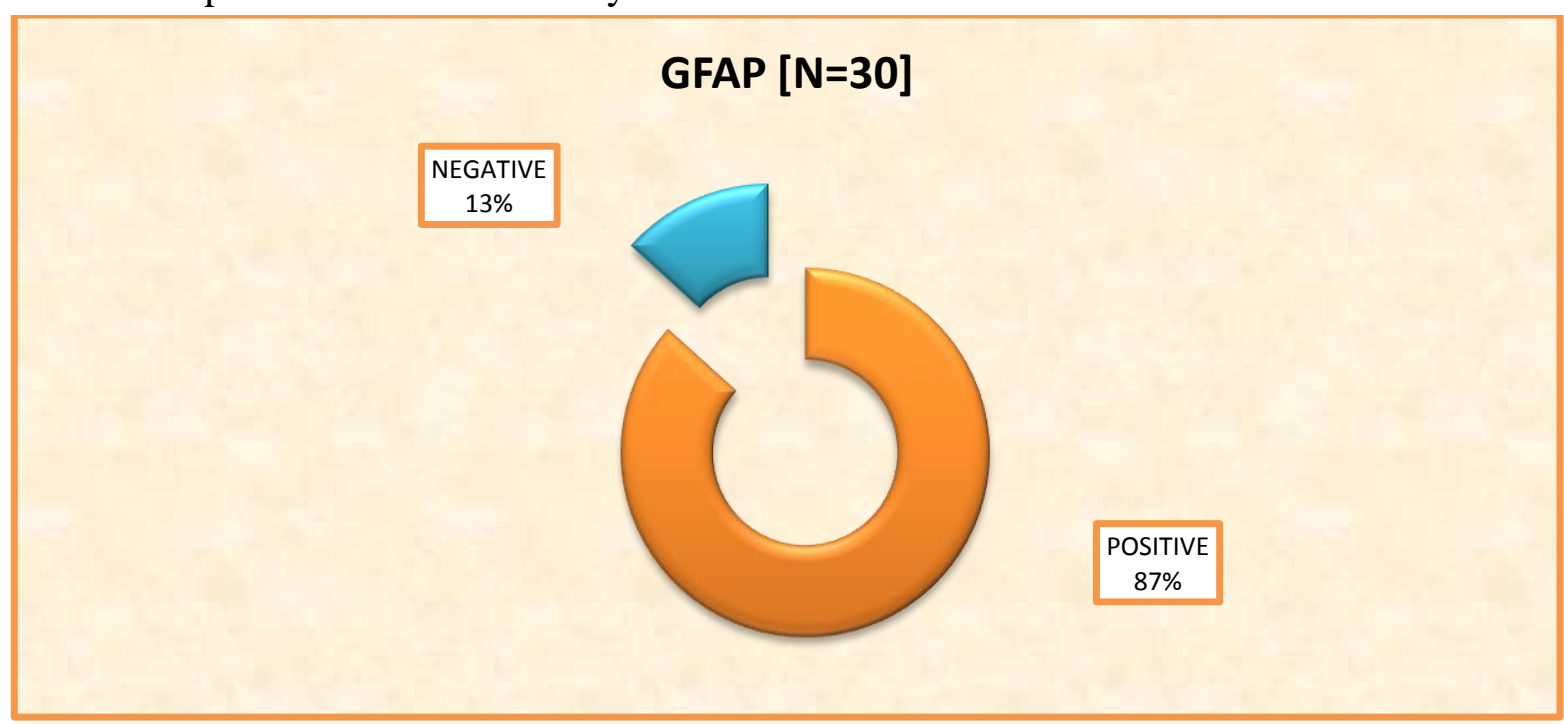


Chart 3: GFAP Expression by Diagnosis

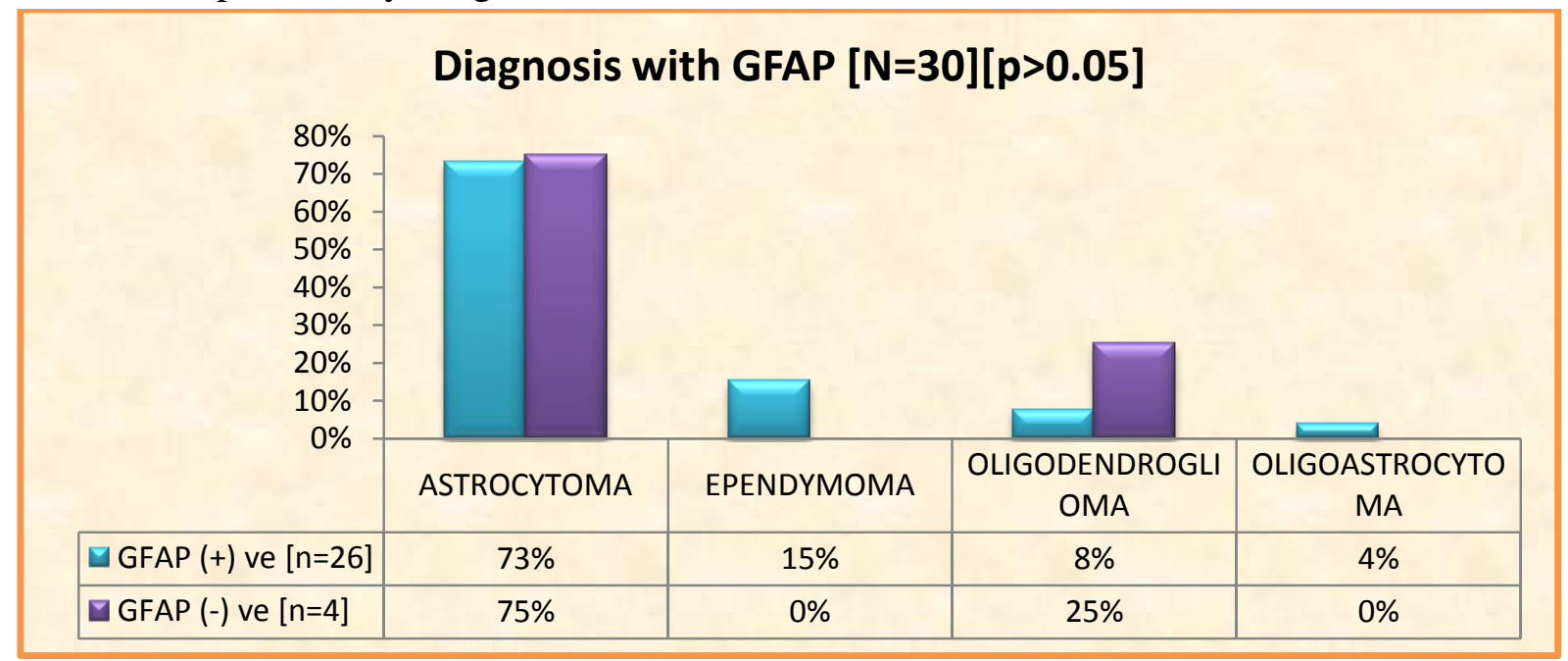

Chart 4: Proportional Score and Grade of Glioma

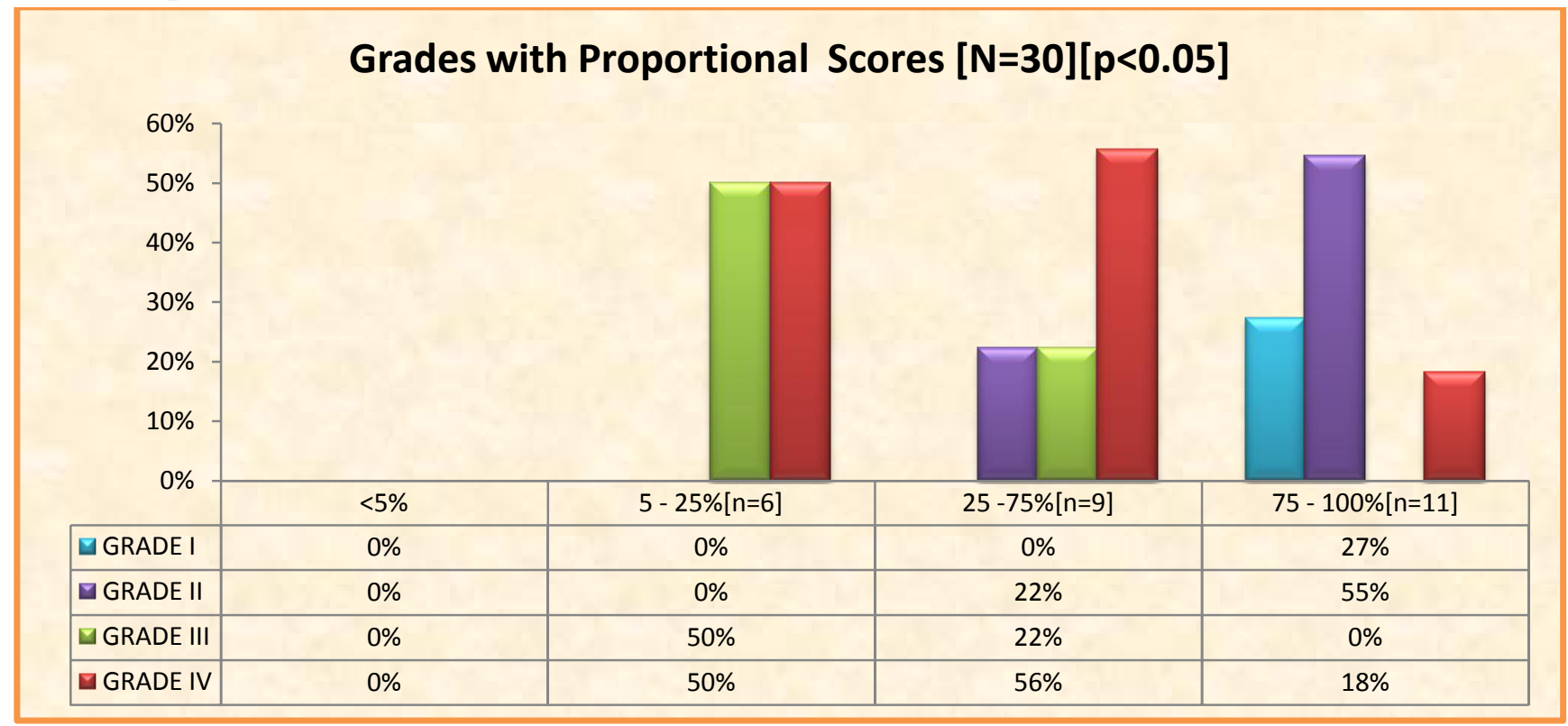

Chart 5: Intensity Score and Grade of Glioma

\begin{tabular}{|r|r|r|}
\hline \multicolumn{3}{|c|}{ Grades with Intensity Scores [N=30] [p<0.05] } \\
\hline $60 \%$ \\
$50 \%$ \\
$40 \%$ \\
$30 \%$ \\
$20 \%$ \\
$10 \%$ \\
$0 \%$
\end{tabular}


Chart 6: Total Score and Grade of Glioma

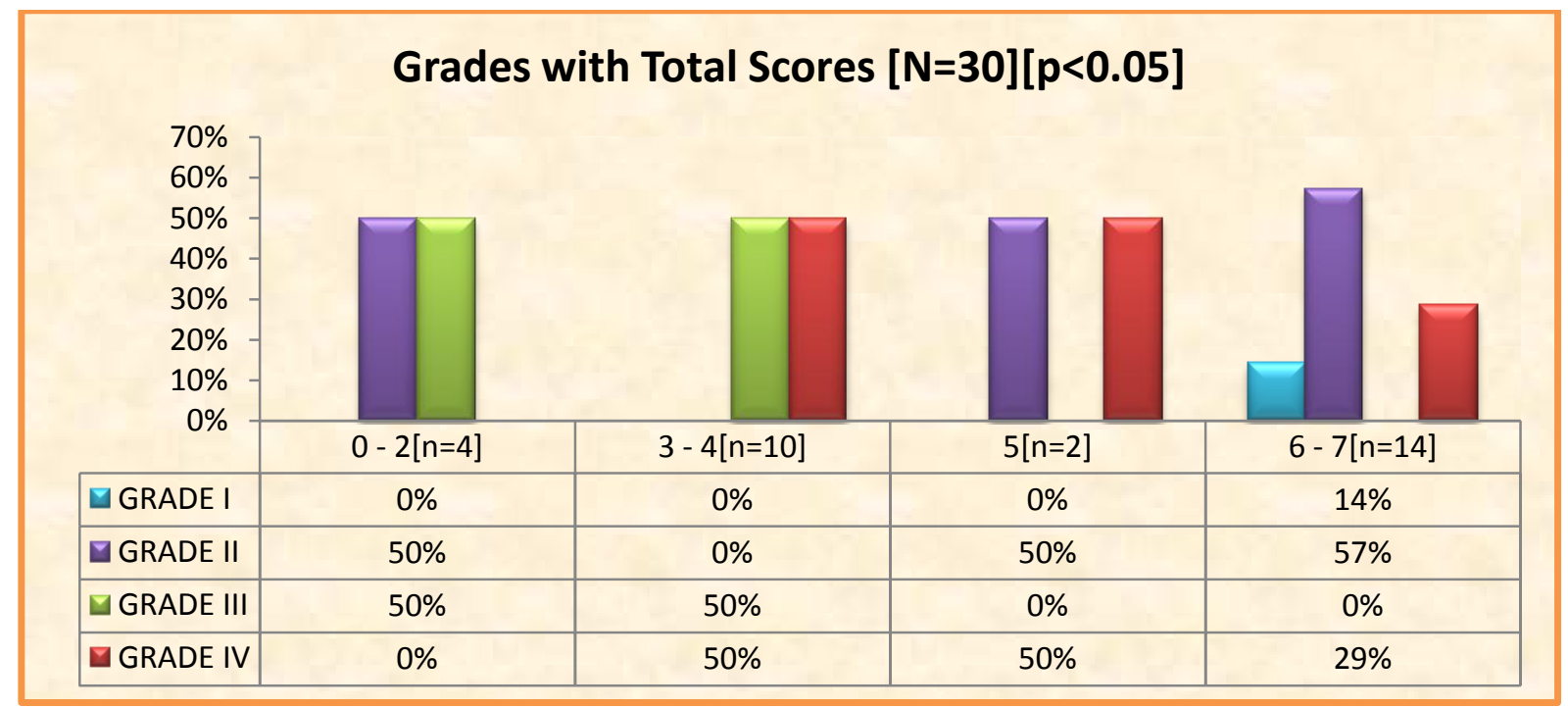

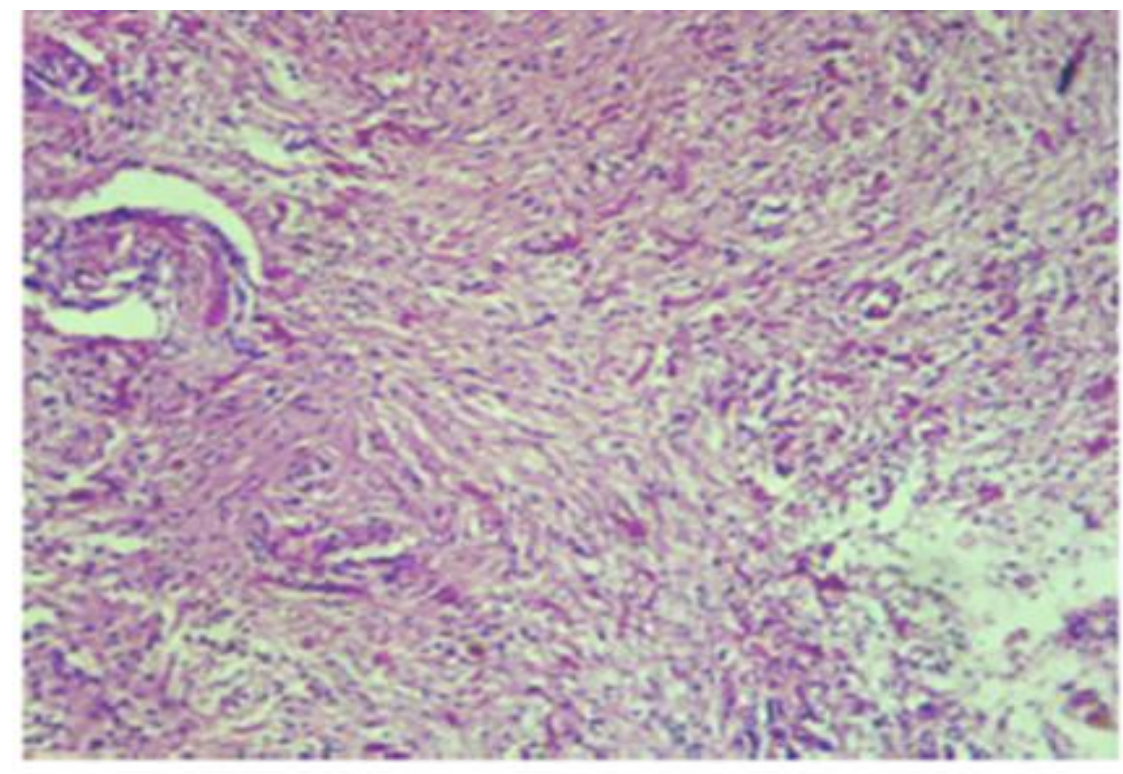

VIE 1: HAE PILOCYTIC ASTROCYTOMA GRADE I (10X)

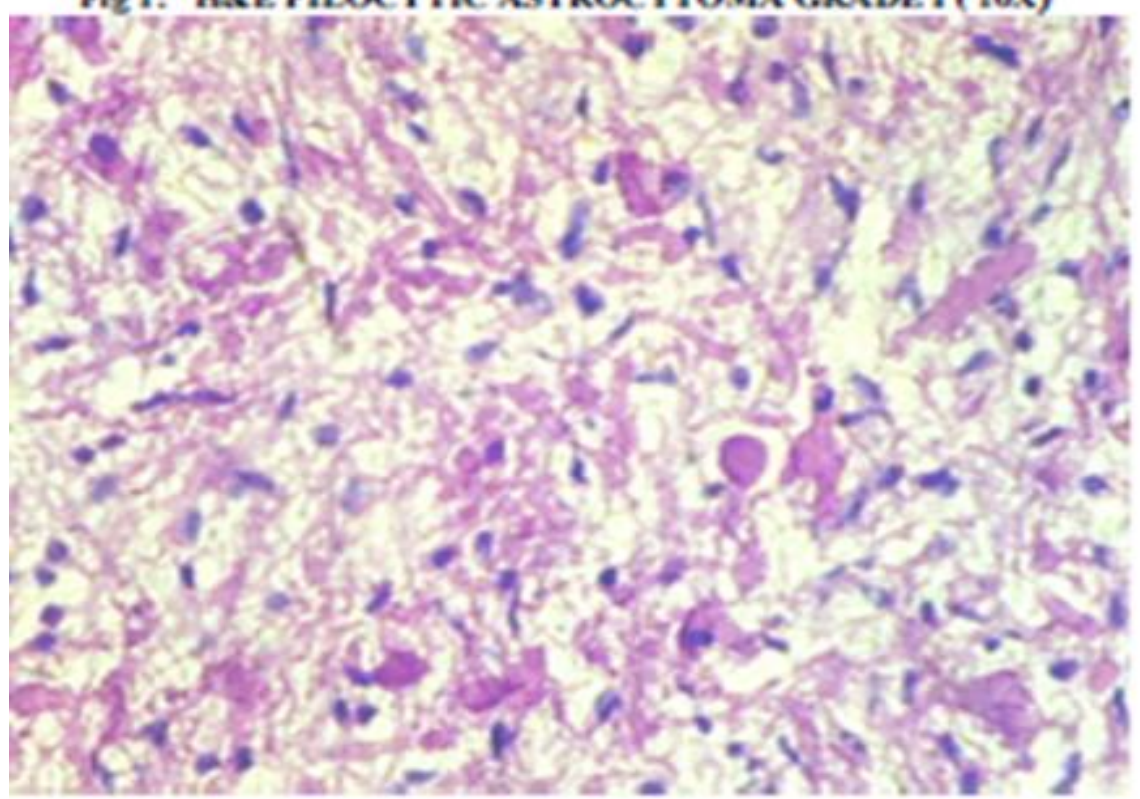

Fig 2: HAE PILOCYTIC ASTROCVTOMA ( 40X) 


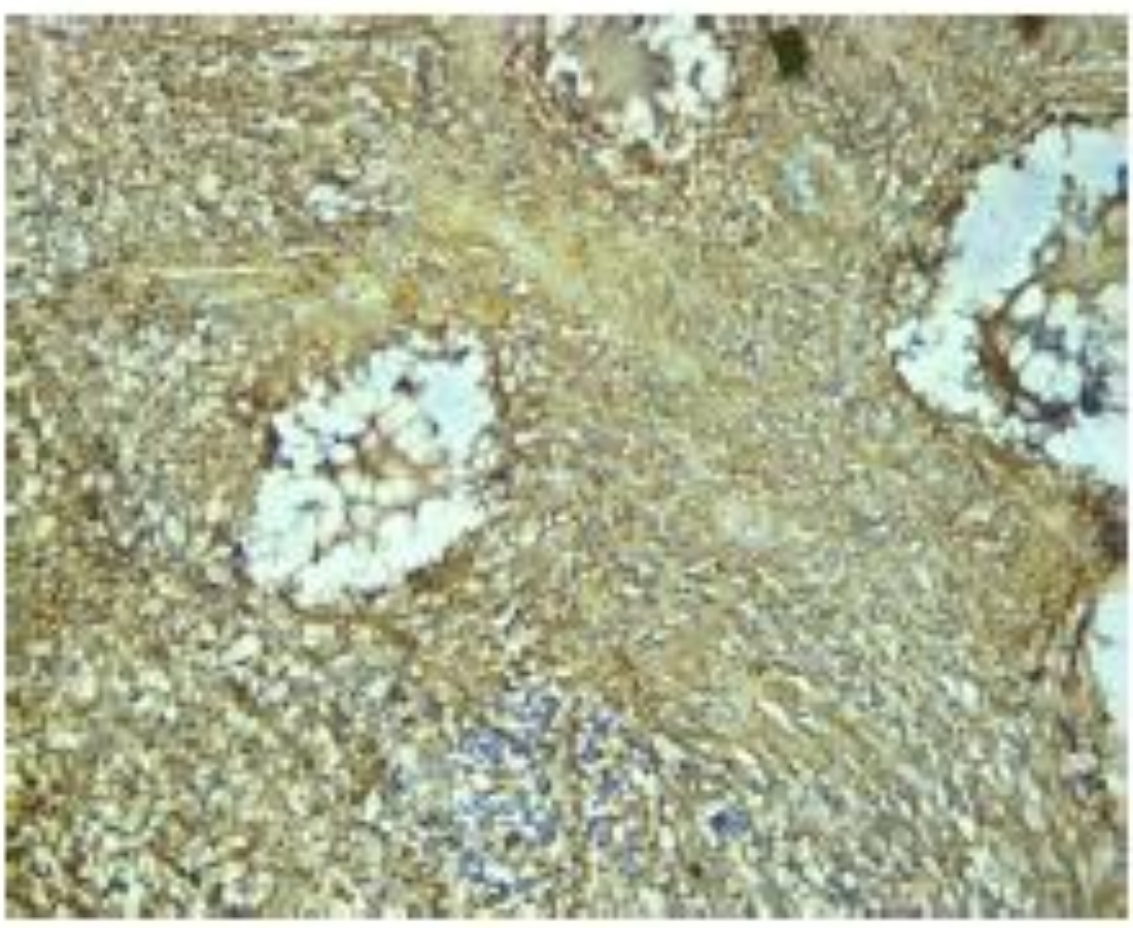

Fig 3: IHC PLLOCYTIC ASTROCYTOMA ( GRADE 1) (10X)

TOTAL SCORE 7 (4PS+3IS)

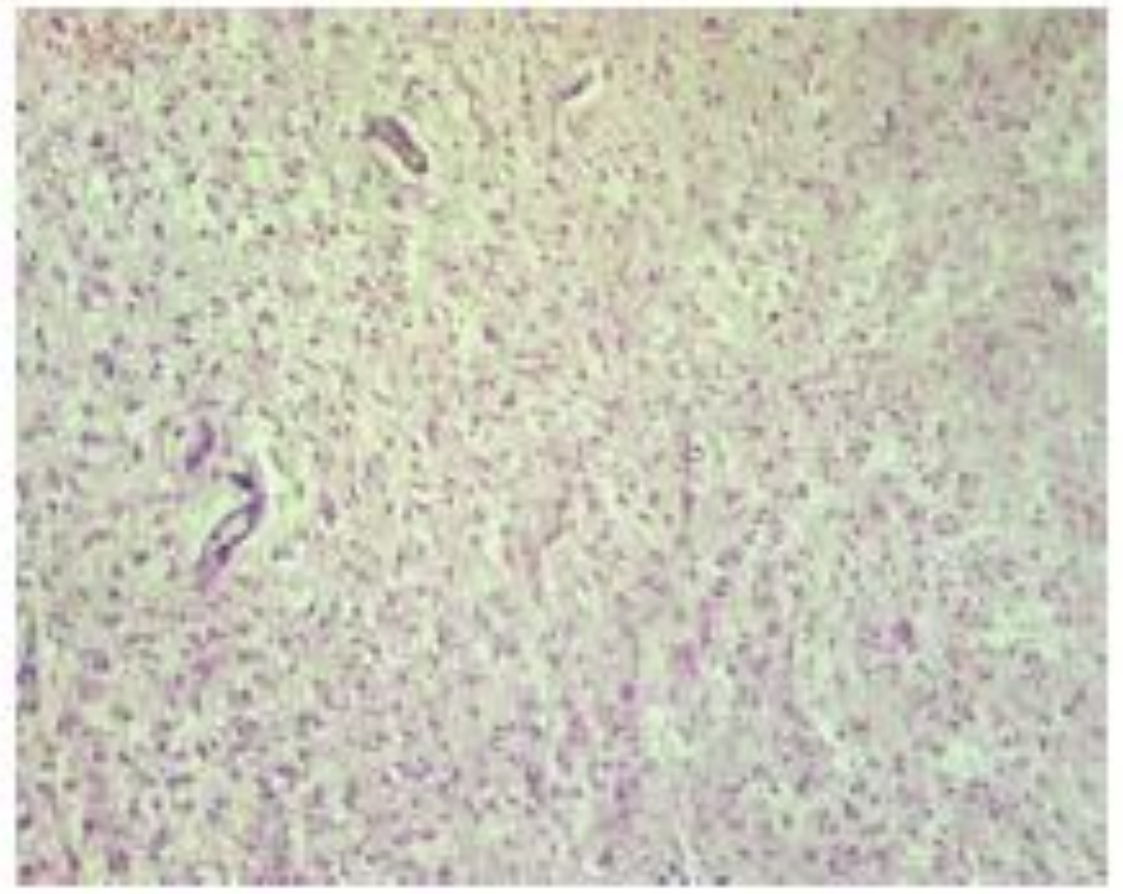

Fig 4: HAE DIFTUSE ASTROCYTOMA GRADE D( 10X) 


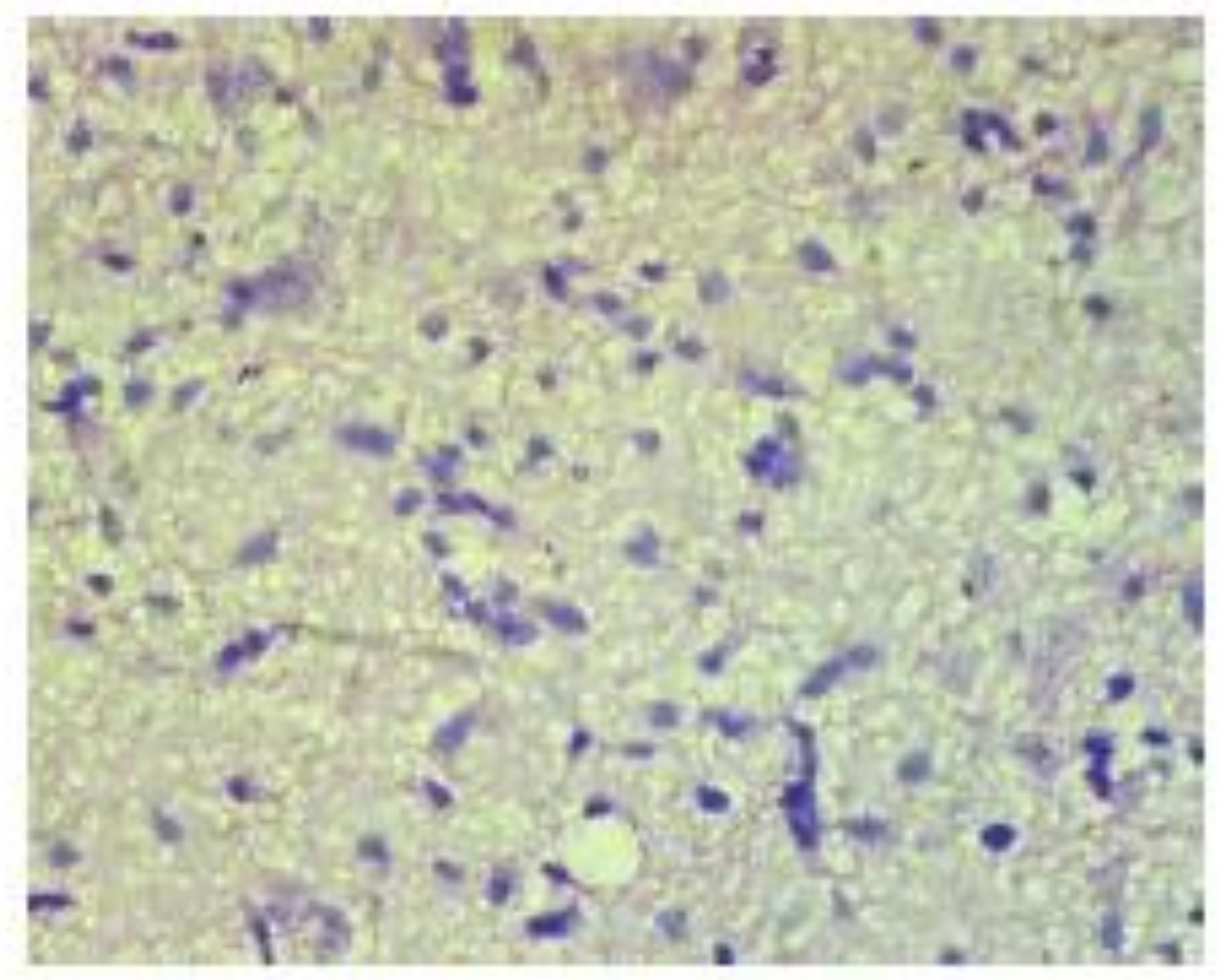

Fig 5. HAE DAFFUSE ASTROCYTOMA (40X)

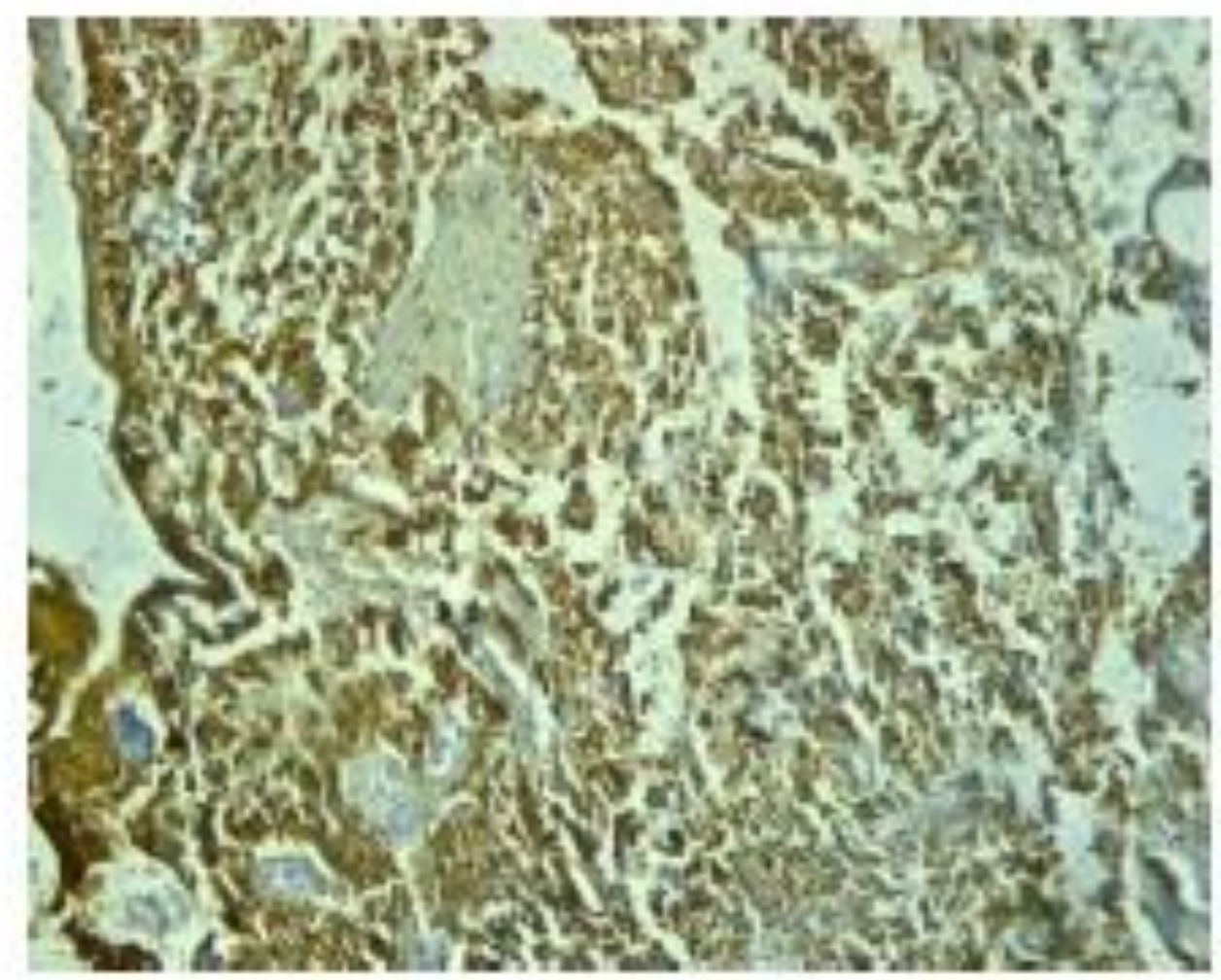

Fig 6: IHC ASTROCYTOMA (GRADE, II) (10X)

TOTAL SCORE 7(4 PS+34S) 


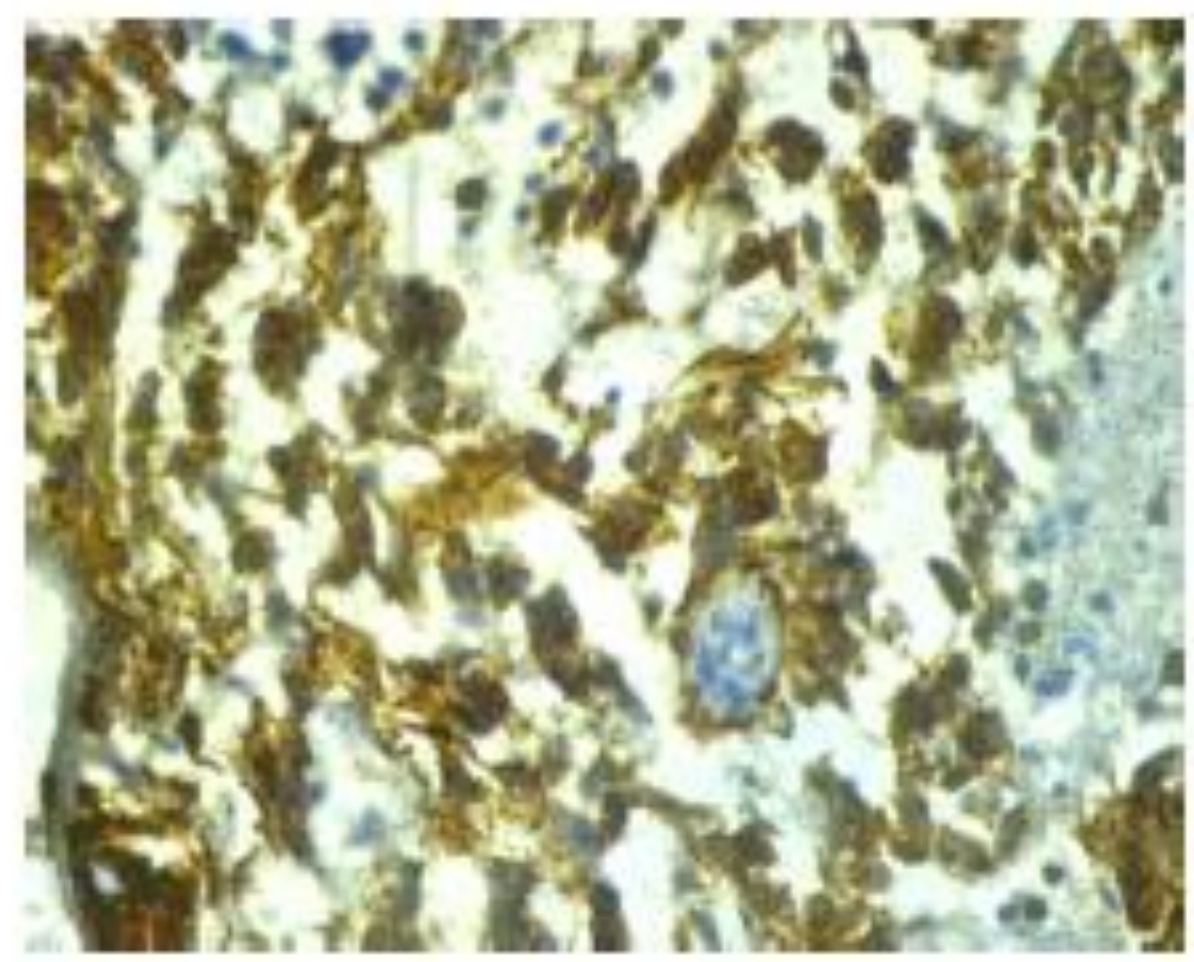

Fig 7: IHC ASTROCYTOMA ( $40 x)$ SHOWING

INTENSE. CYTOPLASMIC GFAP STAINING:

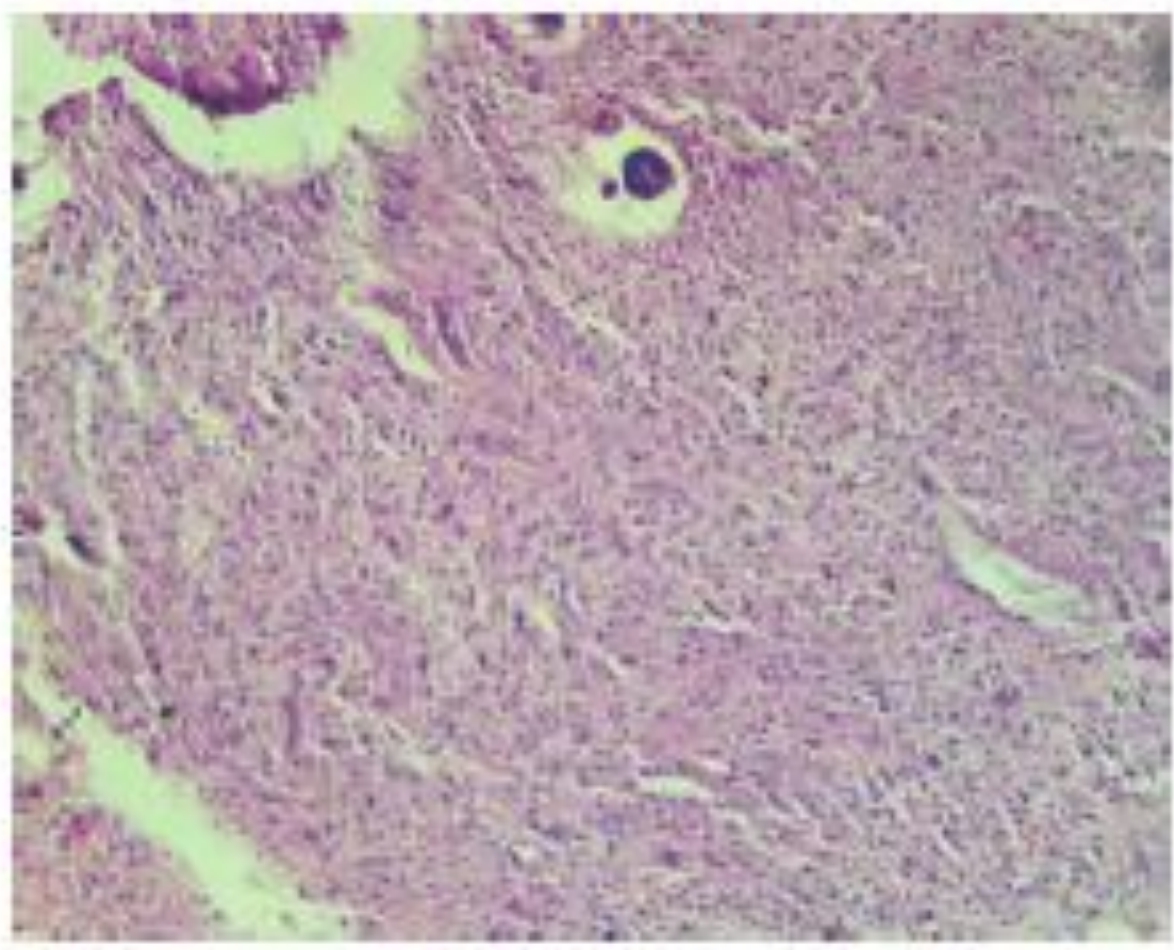

Fïg: HAF. ANAPLASTIC ASTROCYTOMA GRADE III (10X) 


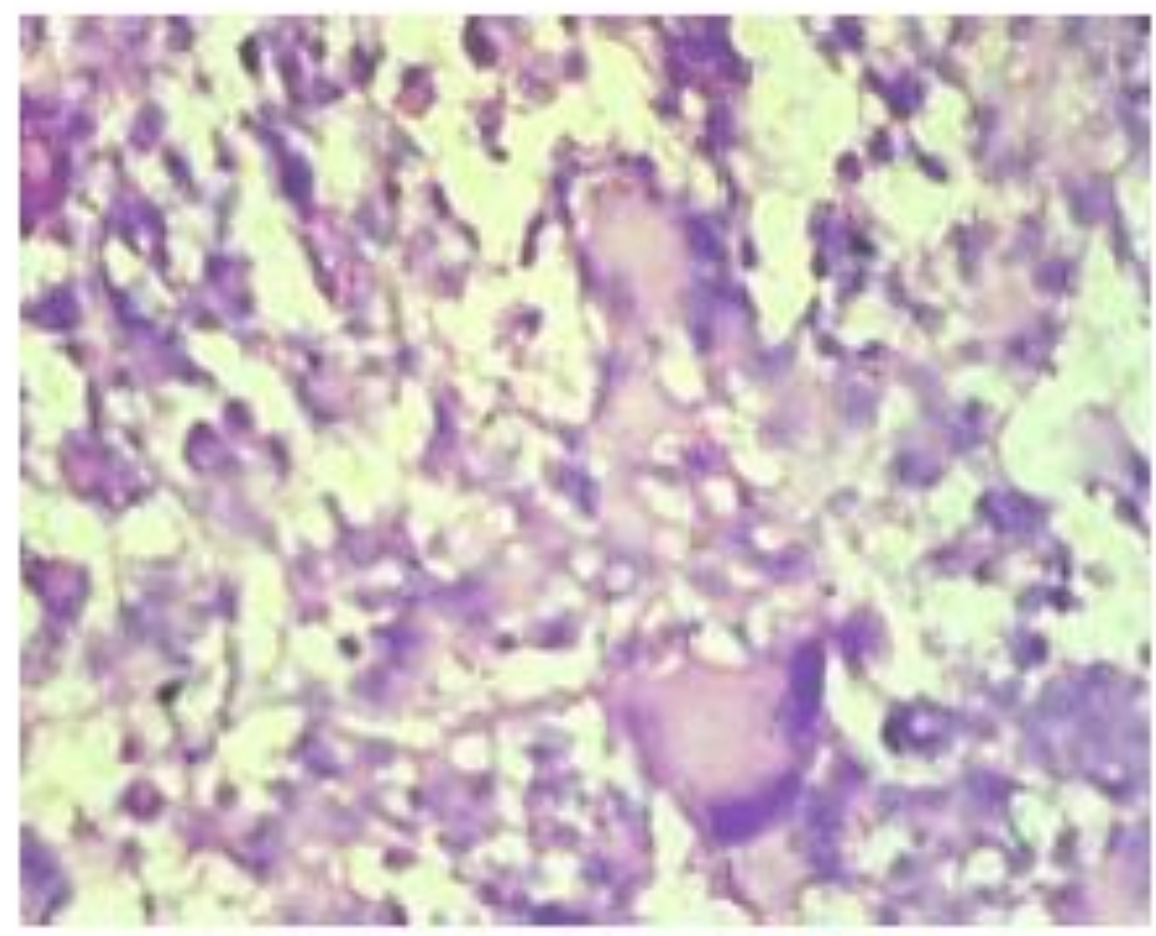

Fig 9: HAE ANAPLASTIC ASTROCYTOMA (40X)

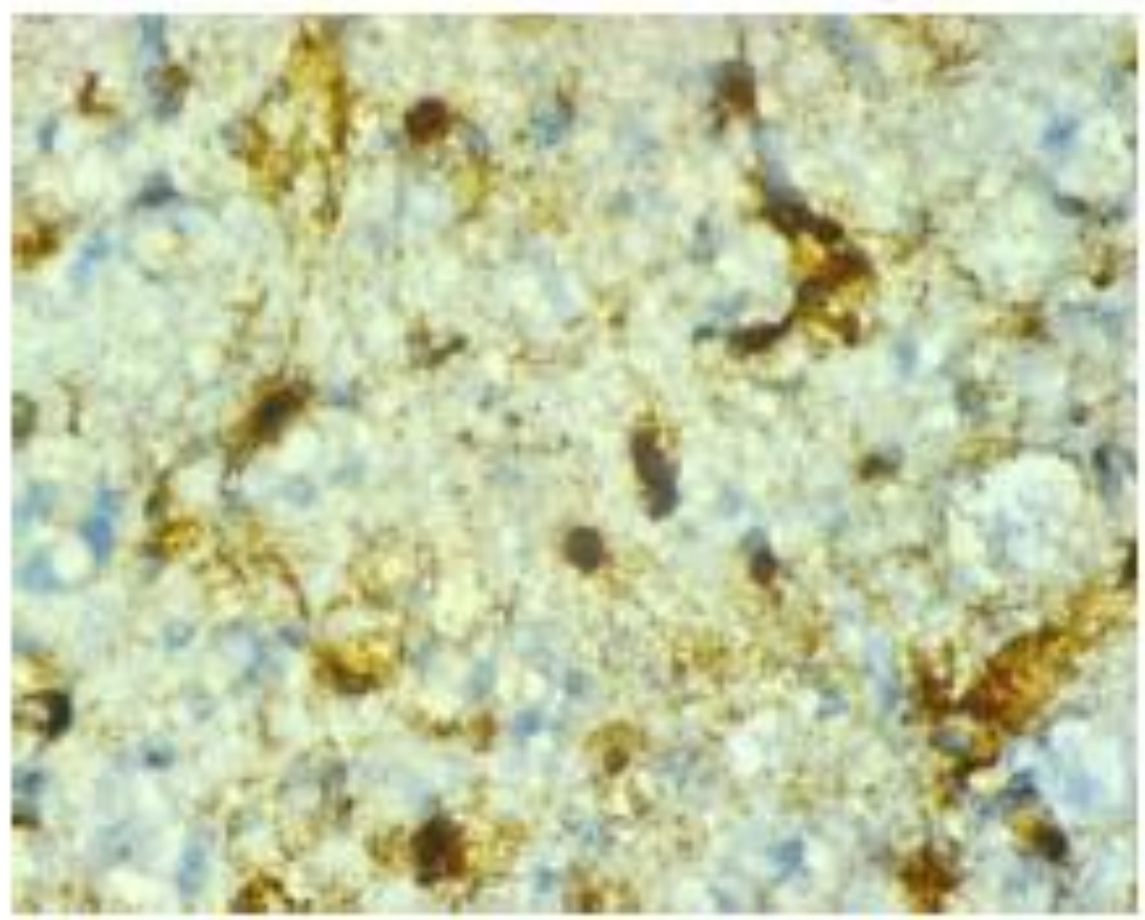

Fig 10. IHC ANA H.ASTIC ASTROCYTOMA GRADE III

TOTAL SCORE 4 (2PS+21S) 


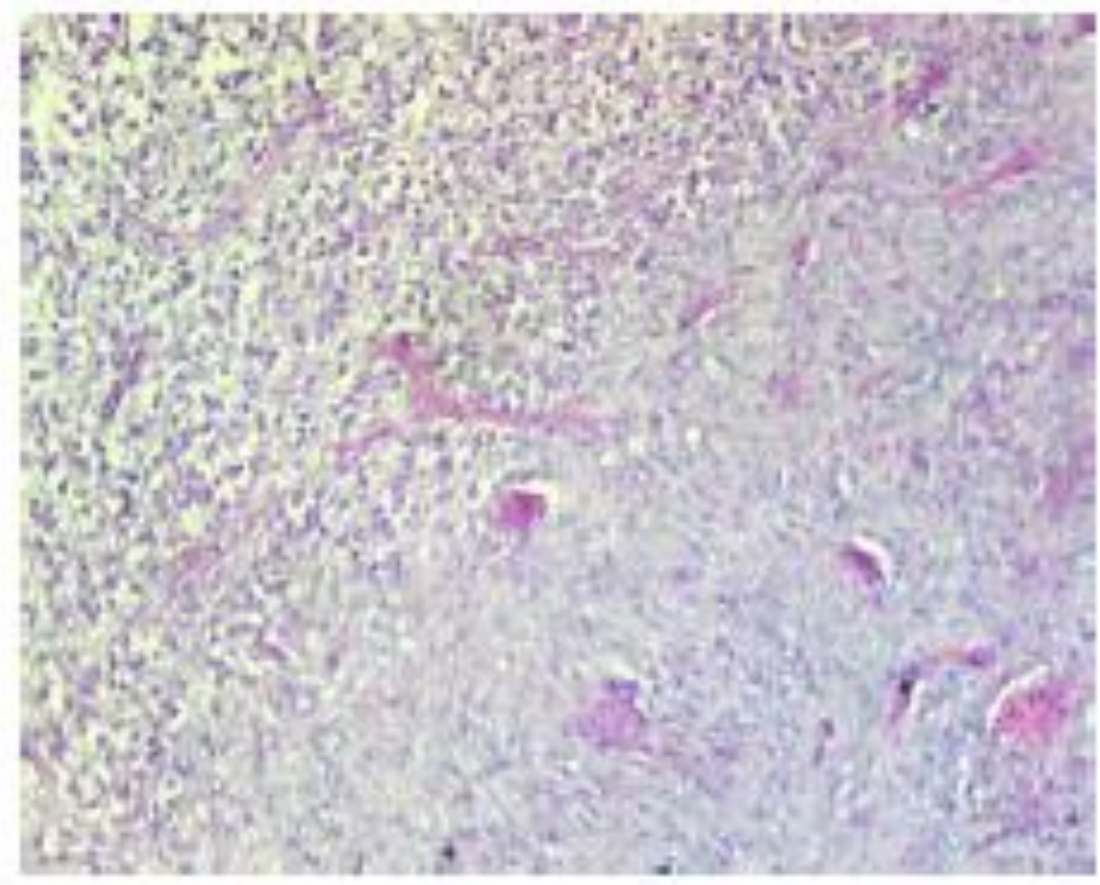

Fig II: H\&E OLIGASTROCYTOMA (10X) GRADE III

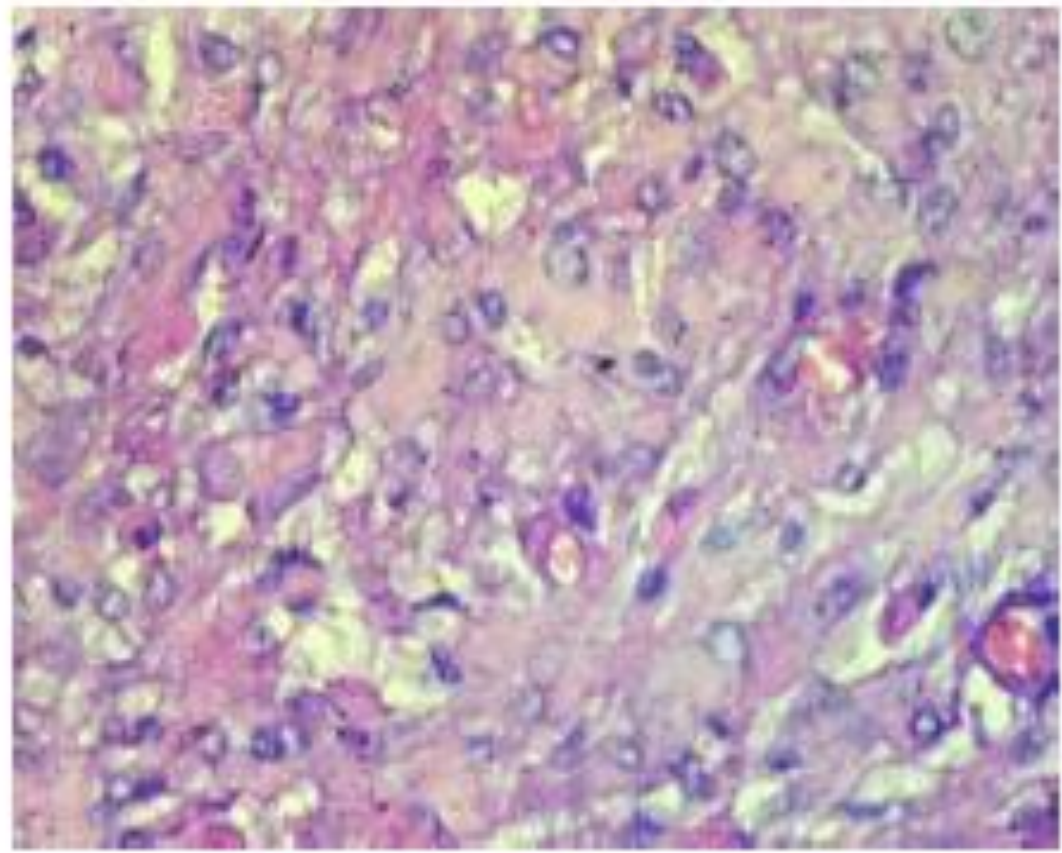

Fig 12: H\&E OL.IGASTROCYTOMA (40X) 


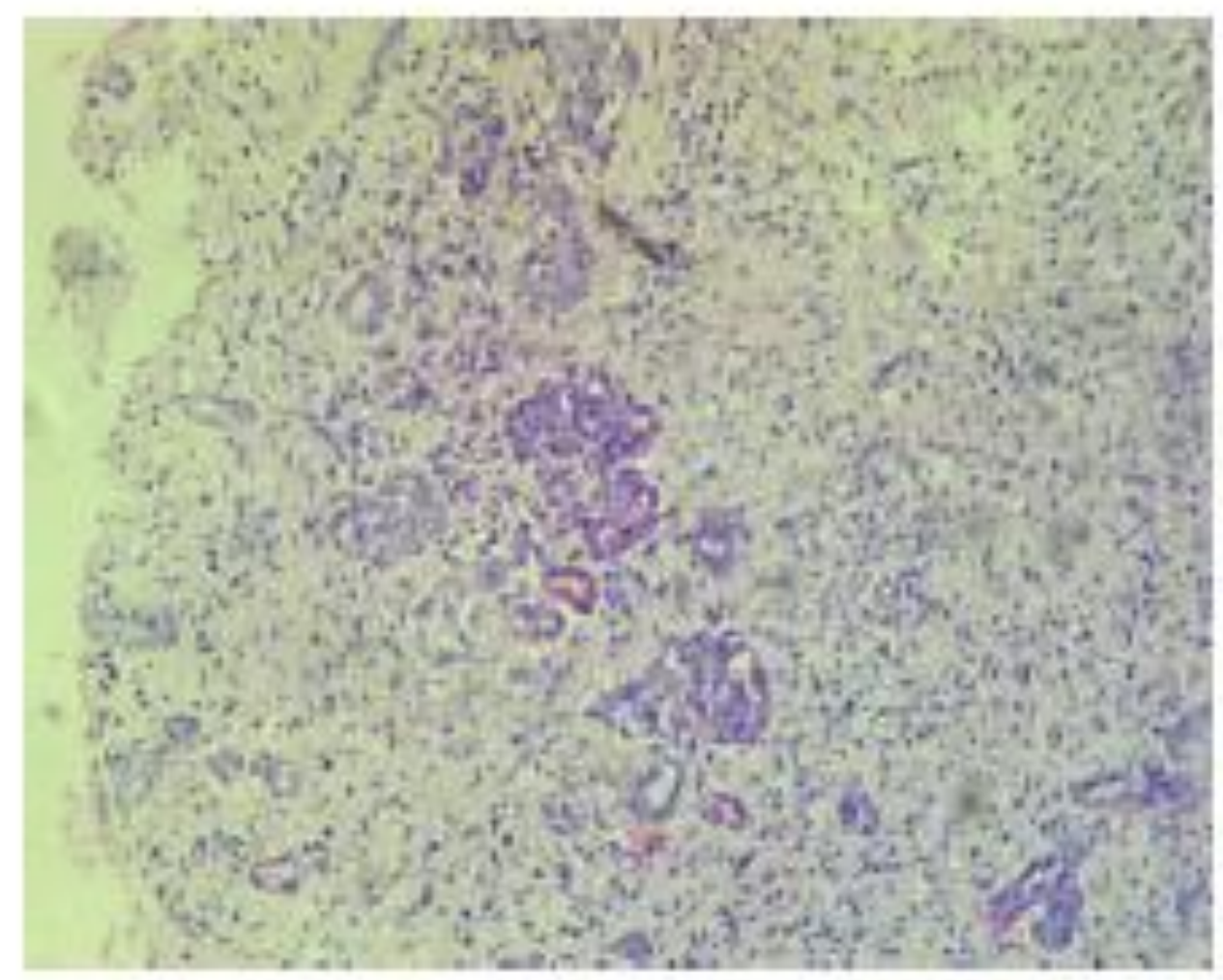

Fie 13: HAE GBM WTTH VASCUL.AR PROLLFERATION GRADE IV (10X)

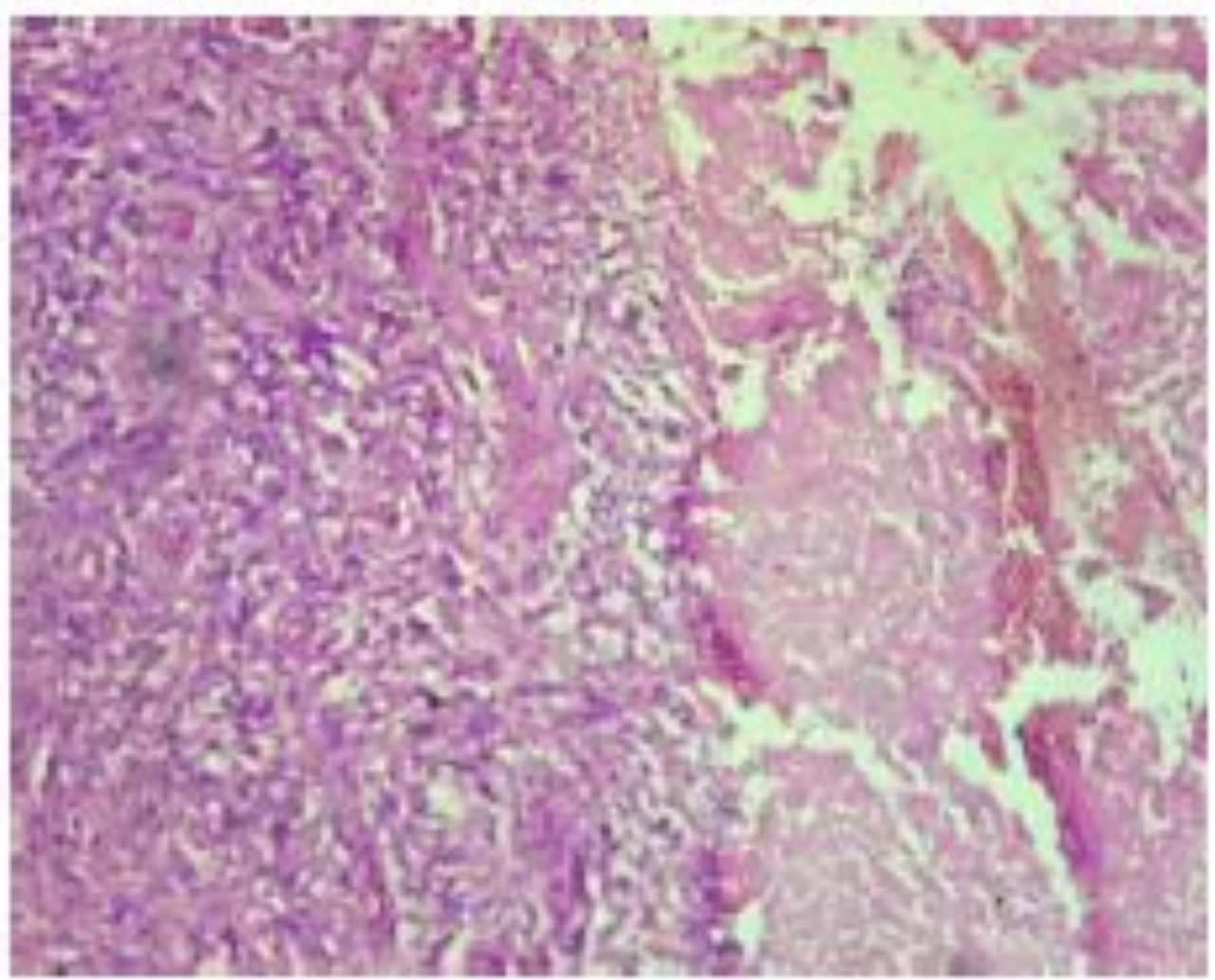

Fig 14: H\&E, GBM WTH NECROSIS (10X) 


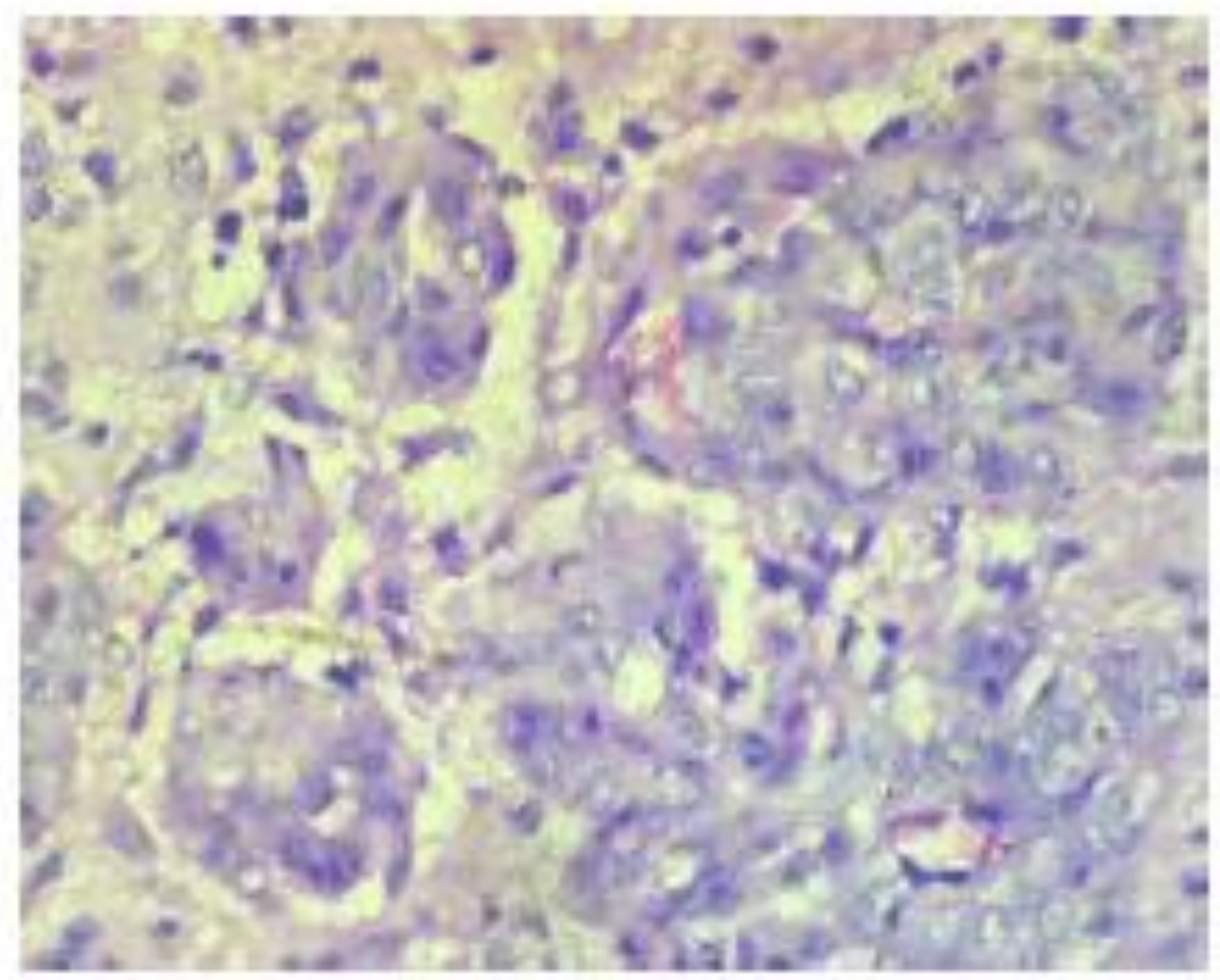

F⿻コ一ำ 15: HAE GL.VOBLASTOMA MULTIFORME (40X)

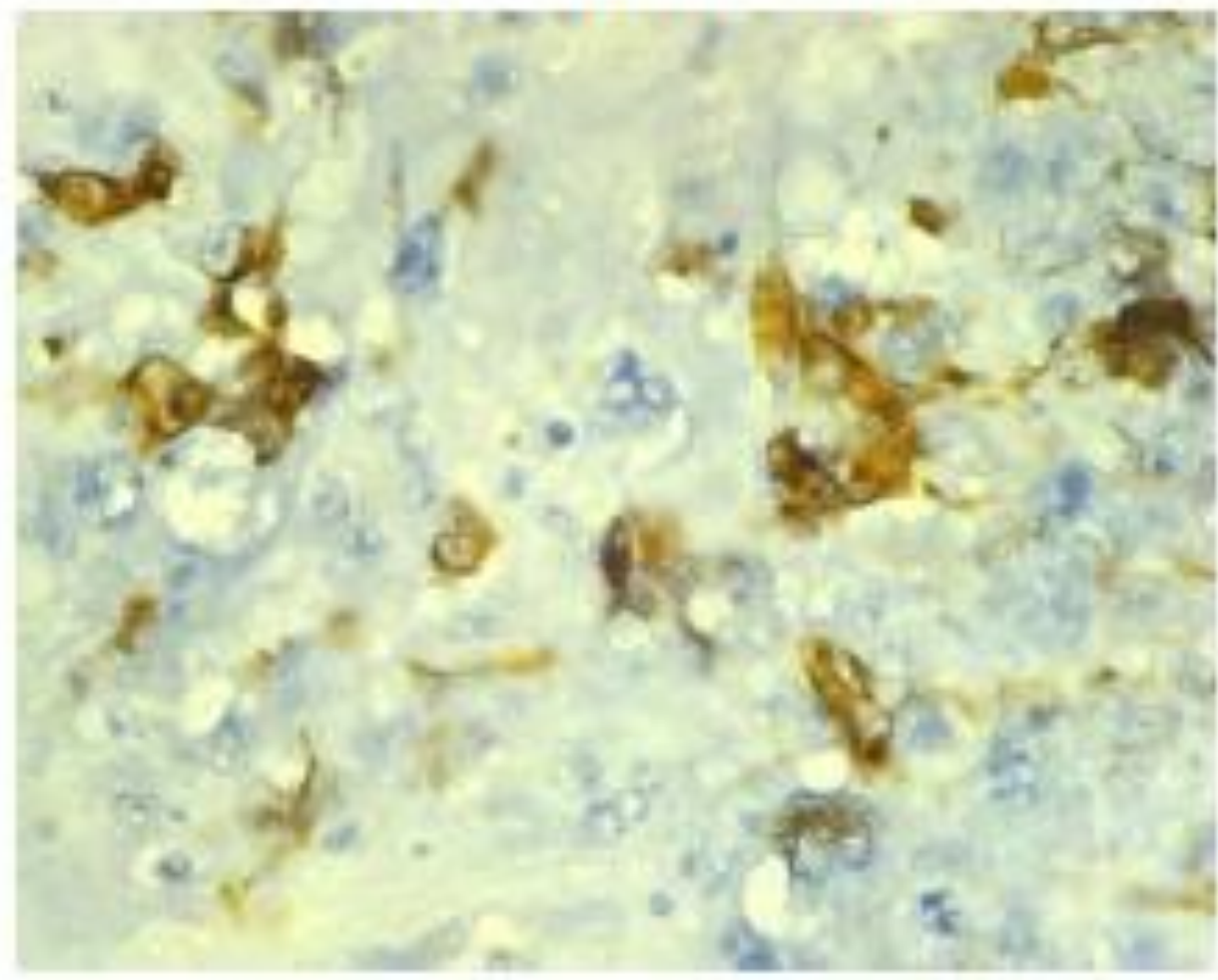

Fie 16: IHC GLIOBLASTOMA MULTIFORME GRADE IV (40X) TOTAL SCORE 3(2PS+1IS) 


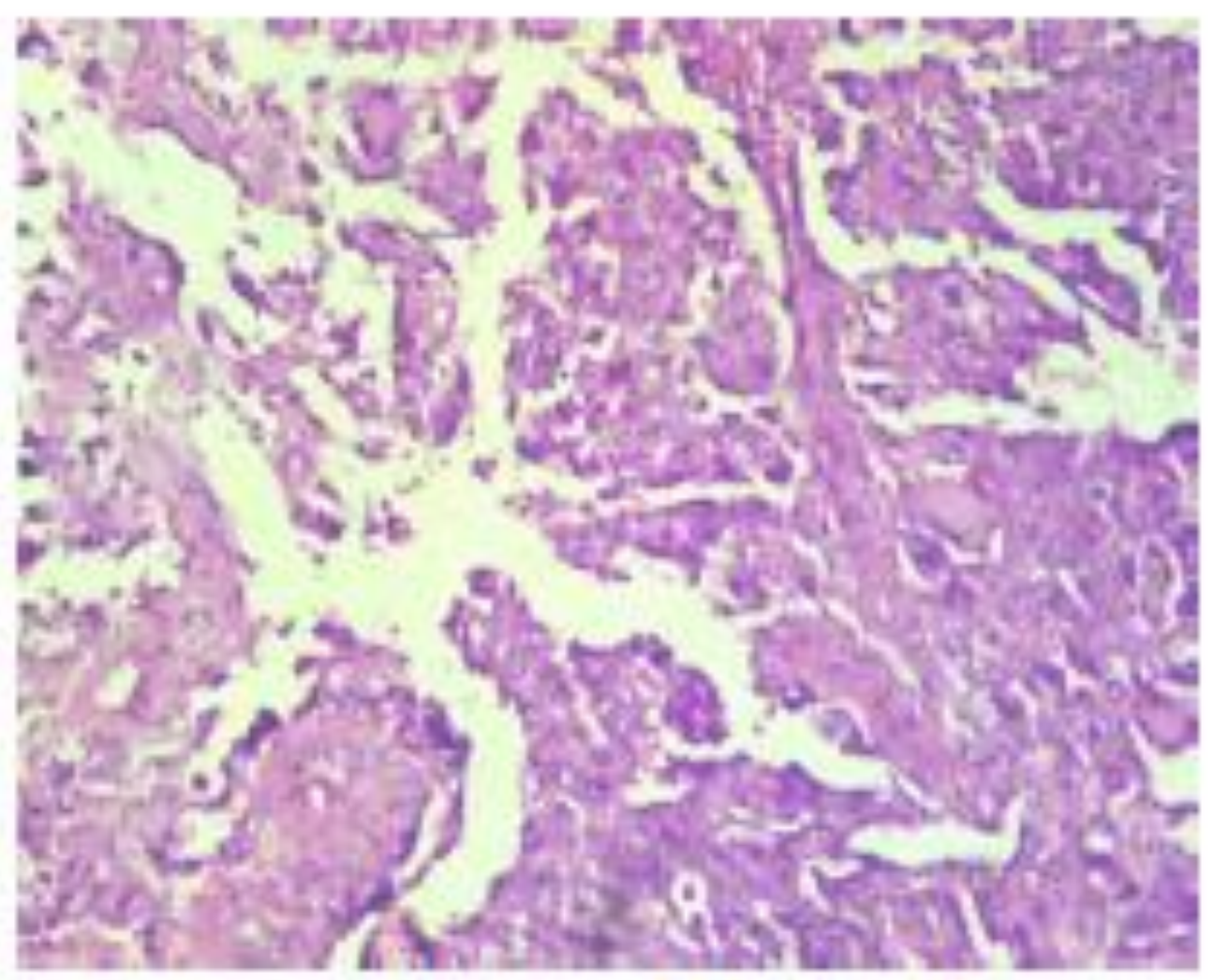

Fig 17: HAE GLANT CELL GHM GRADE IV (IOX)

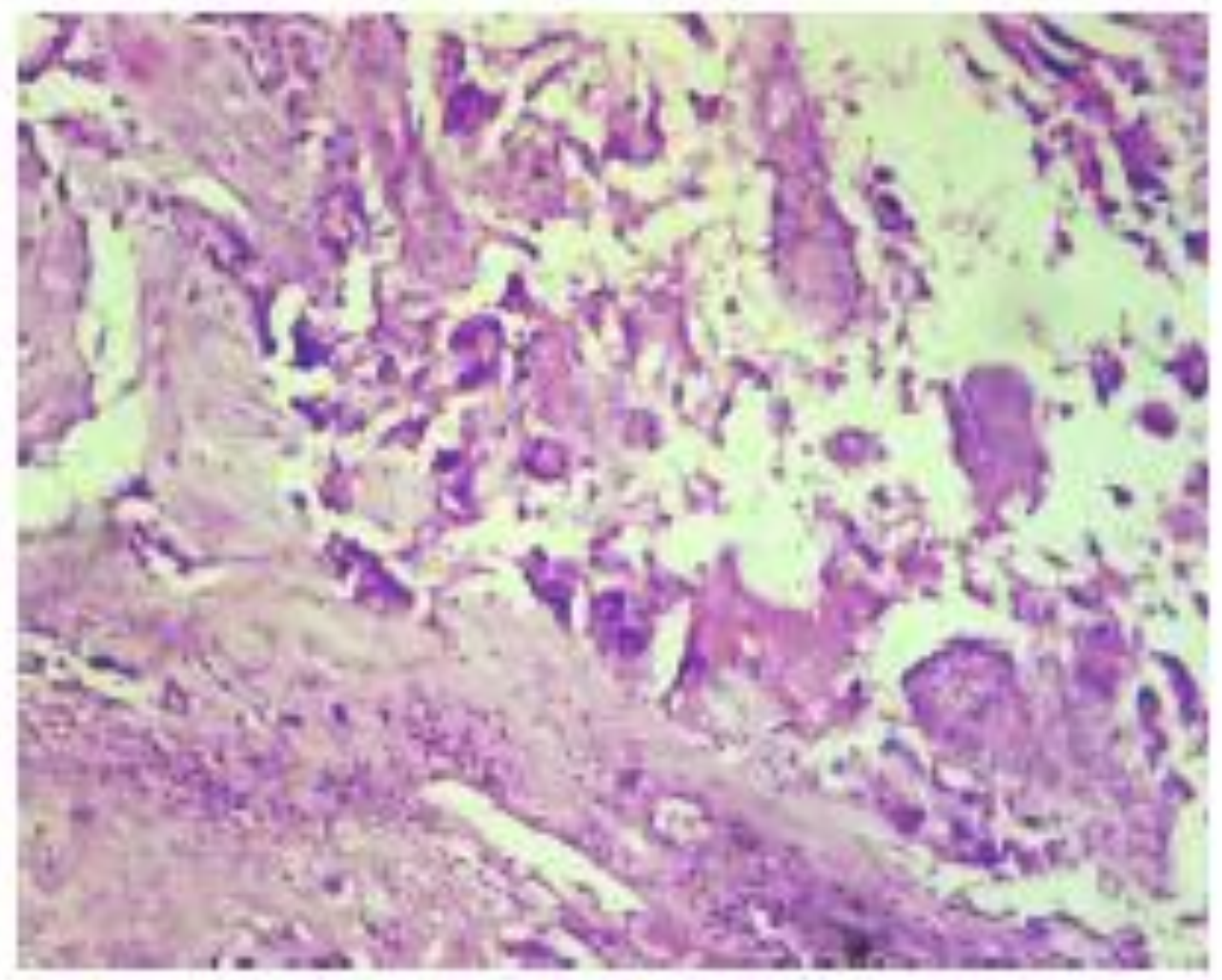

Fig 18: H\&E GIANT CFIL GBM (10X) 


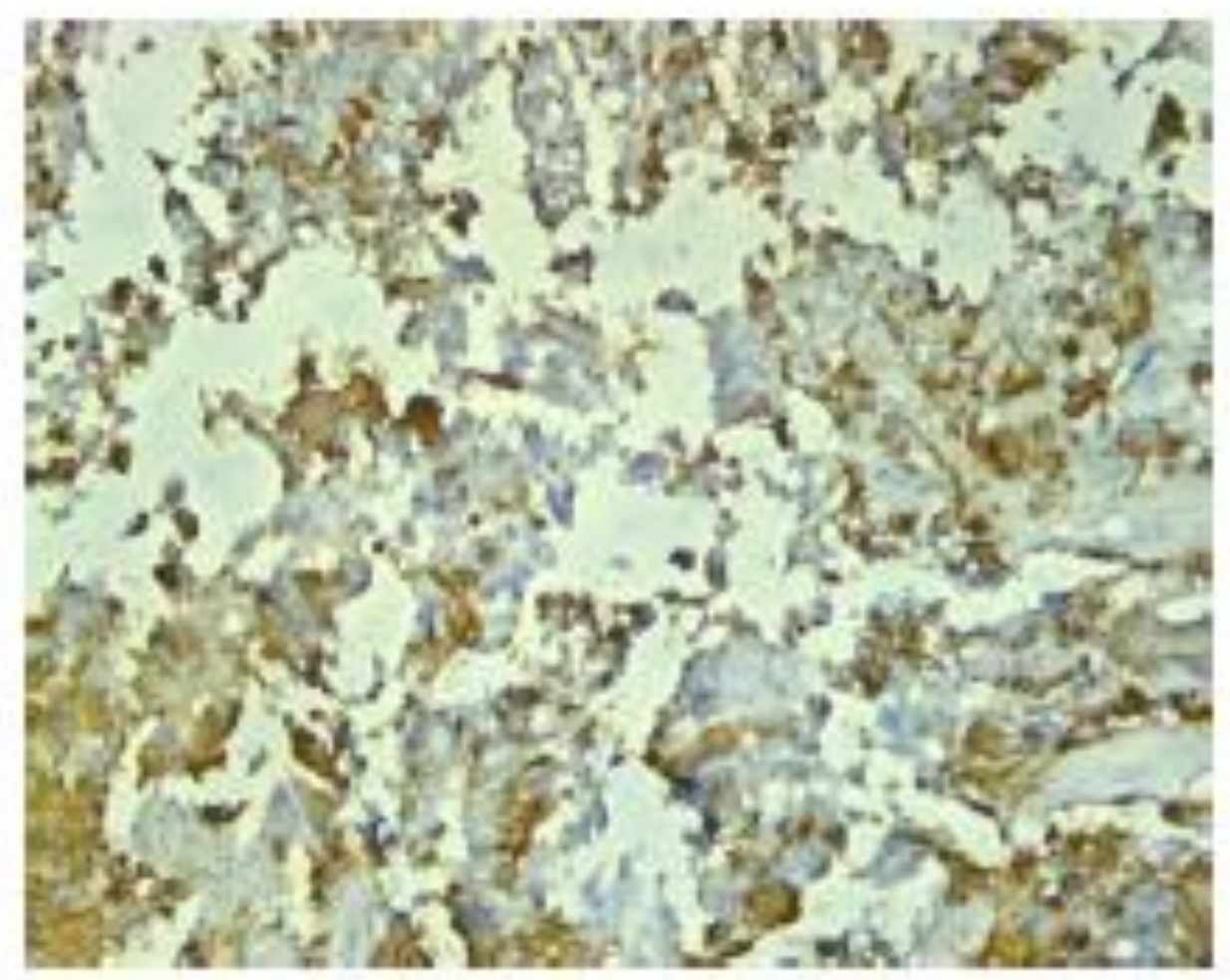

Fig 19: IHC GLANT GHM (10X)

TOTAL SCORE 6(3PS+31S)

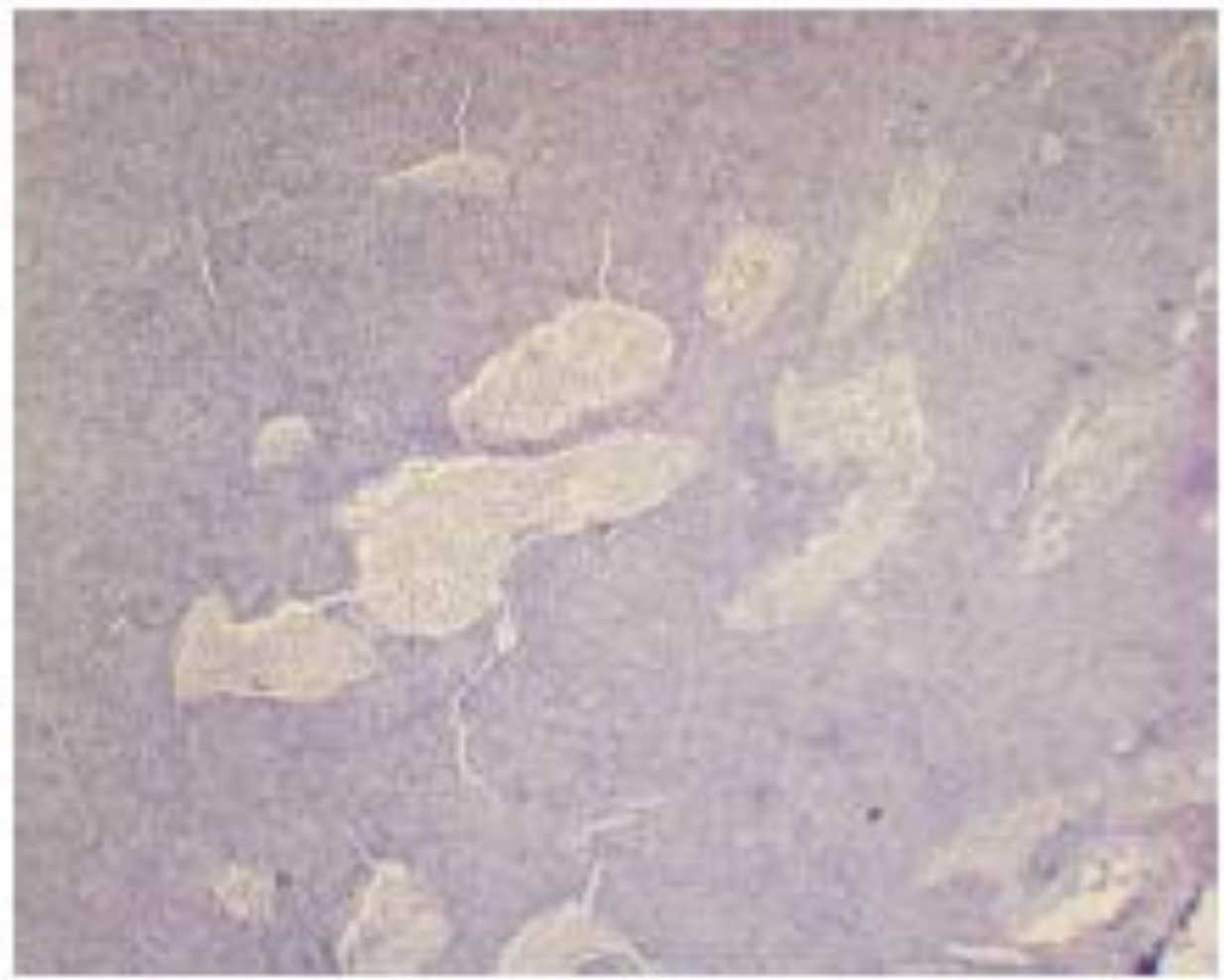

Fig 20; H\&E GL.MOSARCOMA GRADE IV(10X) 


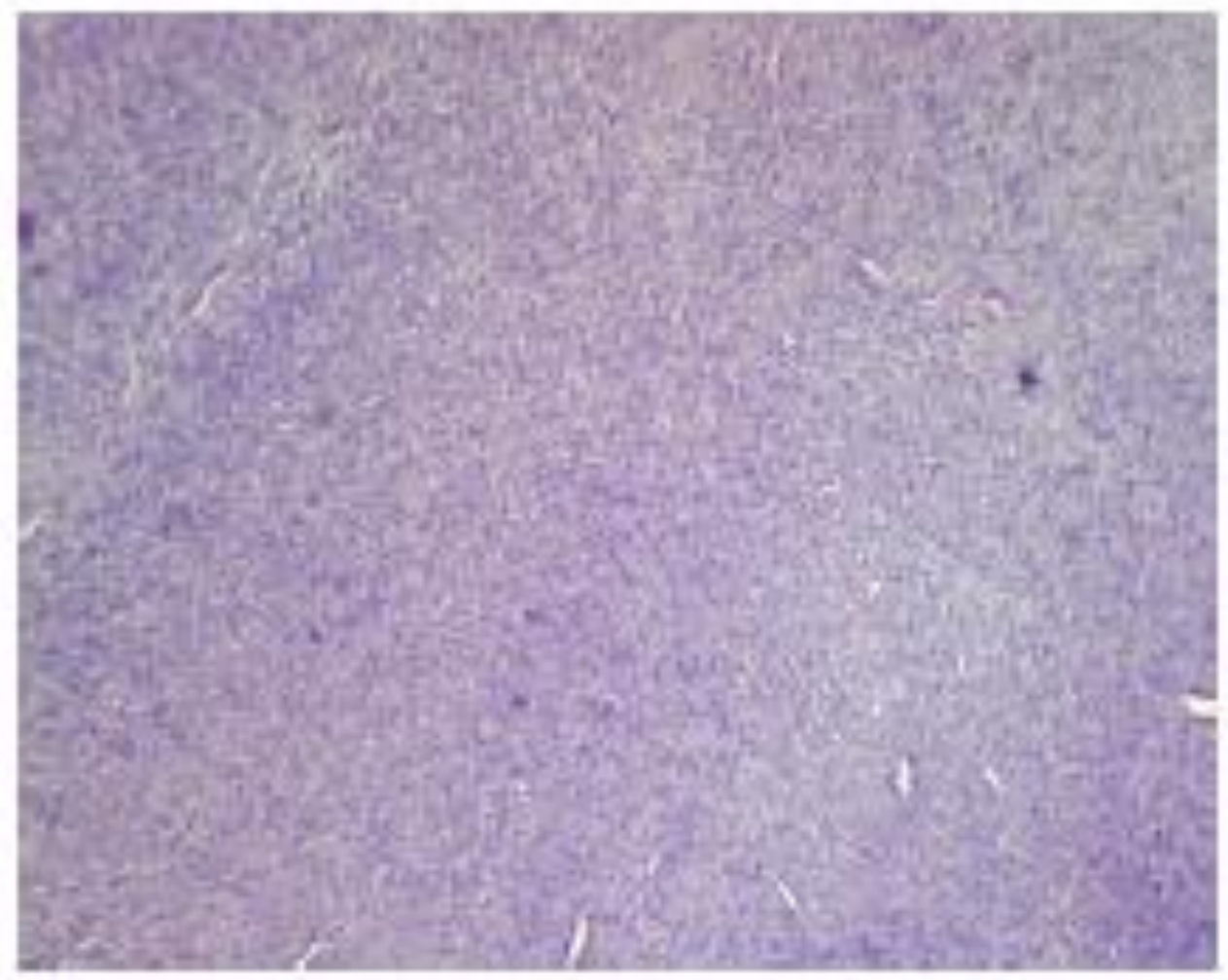

Fïg 21: HAF GL.LOSARCOMA SHOWING SARCOMATOUS AREMLOX]

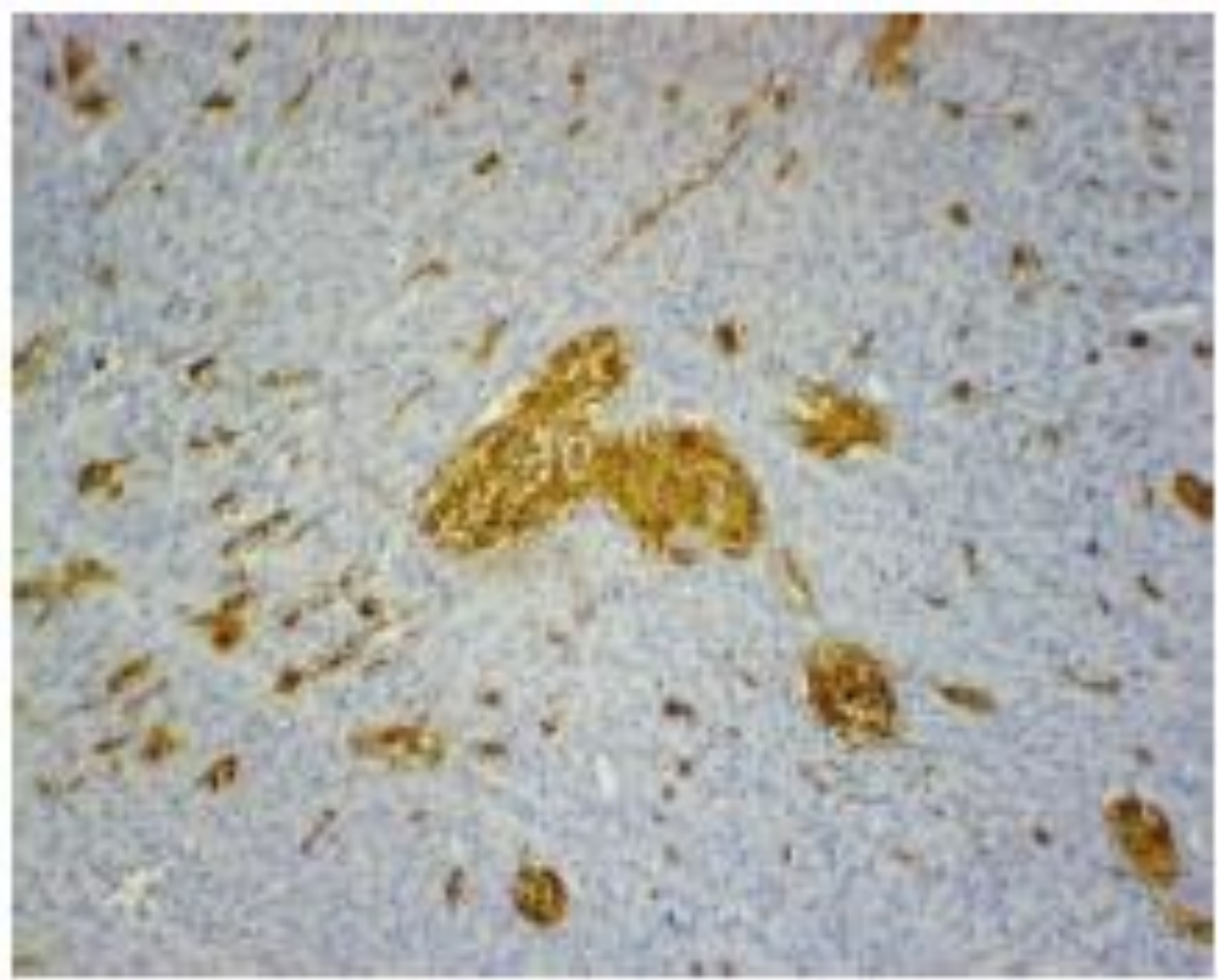

Fig 22: IHC GFAP GL.IOSARCOMA (IOX) SHOWING INTENSE. GFAP EXPRESSION 


\section{Discussion}

Glioma is the most common primary neoplasm of brain arising from the supporting tissues of brain. It occurs in all age group but mostly in adults. Glioma has slight male predominance. Clinically presents with seizures, head ache, personality changes and weakness.

Gliomas are classified into low grade and high grade depending on the aggressiveness and growth potential. The ultimate treatment of patient depends on the proper diagnosis. The diagnosis is done with the help of neurological examination, imaging, and histopathological studies. Though histopathological examination is conclusive and diagnostic there lies some diagnostic dialemmas so ancillary studies such as immunohistochemistry and cytogenetics have given new dimension in diagnosis of glial tumours.

The present study evaluates the immunohistochemical expression of glial fibrillary acidic protein (GFAP) in glial tumours and its correlation with grade of glioma.

Neoplastic astrocytes share in common with normal in presence of intermediate cytoplasmic protein known as glial fibrillary protein which is detected by immunohistochemistry. GFAP status helps in confirmation of diagnosis and degree of tumour differentiation. Studies show that there is inverse correlation between GFAP expression and grade of glioma.

The overall age range of 30 patients included in the present study was 1 to 70 years with a mean of 40 years and median age of 50 years.

Maximum percentage of patients (33\%) belonged to the age group of 51-60 years followed by patients between 31-40(17\%) and 1-10(17\%).

Inasimilar study done by Dr.Jalal A. Jalal et al, largest number of patients belonged to 41-50 (23\%) age group. ${ }^{97}$

In another study done by, Madabhushi, et al.: the maximum number of cases was in the age group of 41-50 yrs. And study from pakistan observed maximum number of cases in third and sixth decade of life. ${ }^{99}$
We observed an overall approximate male to female ratio of 1.3: 1 . A male preponderance was noted amongst patients with glial tumours.

This correlates with study from Pakistan which had male to female ratio of $2.33: 1^{1}$

A study by Dr. Jalal A. Jalal et al also observed slight male preponderance with male to female 1.6:1. ${ }^{97}$

In present study majority of cases were supratentorial accounting to $73 \%$ and remainder were infratentorial. This correlates with study done by Dr. Jalal A. Jalalet al where supratentorial tumours constituted to around $61.5 \%$ and infratentorial tumours about $38.5 \%{ }^{97}$

In current study adult tumours were mostly supratentorial (92\%) and childhood tumours were all infratentorial (100\%).

According to Kenneth Chukwuka Katchy et al, $57 \%$ of childhood tumour and $27 \%$ of adult cases were infratentorial which correlates with the present study.

In present study GFAP expression was positive in $87 \%$ cases of glial tumours and negative in $13 \%$ cases. This result agrees with that reported by Wahda M. Al-nuaimy et al. who revealed positive GFAP expression in $96 \%$ cases of glial tumours and similar results were seen in study done by Trevor Jones $\mathrm{R}^{101}$ and Gullotta et al. ${ }^{102}$

In present study astrocytoma are more common than other glioma and intense GFAP expression is seen in $73 \%$ cases. This is similar to study done by Wahda M.Al-nuaimy et al. where $75 \%$ cases of astrocytomas had positive staining. ${ }^{100}$ This also correlates with study done by byDr. Jalal A. Jalalet al. where positive staining in astrocytoma was seen in $77 \%$ cases. ${ }^{97}$

The present study revealed all cases of ependymoma 4(100\%) cases and oligoastrocytoma were positive. This exactly correlates with study done by Wahda M.Alnuaimy et al. ${ }^{100}$ In present study among 3 cases of oligodendroglioma 2 cases showed positive staining for GFAP. This is similar to study done by Wahda M.Al-nuaimy et al. And Vyberg et al. in $2006 .{ }^{103}$ But study by Dr.JalalA.Jalal ${ }^{97}$ had all 
cases of oligodendroglioma positive for GFAP staining.

In present study there was no significant relation existed between age and GFAP expression and with sex and GFAP expression, but study by

Dr. Jalal A. Jalal showed significant relation between age and GFAP expression. And no significance was found between sex and GFAP expression. In present study 19 supratentorial cases and 7 infratentorial cases had positive staining but significance was found. Similar study done by Dr. Jalal A. Jalal had significant correlation between anatomic location of tumour and GFAP expression. In present study there was significant inverse relation between grade of glioma and proportional score on one hand and intensity score and intensity score on other hand with $\mathrm{p}$ value $<0.05$.

This is consistent with the study done by Wahda $\mathrm{M}$. Al-nuaimy et al. and also by Ulrika $\mathrm{W}$ et al in 2003., Maruno $M$ et al., Manuel $\mathrm{E}$ et al. In contrast to this study Tajika et al., Jossef Zamecnuk et al failed to show any significant relation.

In present study there was highly significant inverse relation existed between the total score and grade of glioma with $\mathrm{p}$ value 0.01 . similar results were seen in following studies. Tascos $\mathrm{N}$ A et al., Bian X W, Lalya G S showed inverse relation between grade of glioma. ${ }^{104,105}$ According to study by Wahda M.Al-nuaimy et al grade of glioma and GFAP expression showed inverse relation. ${ }^{100}$ On contrary study by Reyaz $\mathrm{N}$ et al. ${ }^{95}$ showed direct relation Tajika $\mathrm{T}$ et al. ${ }^{106}$ showed no relation between grade of glioma and GFAP expression.

In present study few cases (29\%) of glioblastoma showed high GFAP score which is consistent with study by Wahda M.Al-nuaimy et al., ${ }^{100}$ which had $38 \%$ cases of GBM showing high score. The probable reason could be due to astrogliosis or neoplastic transformation associated aberrant regulation. ${ }^{100}$ All these studies indicate GFAP level reduces with increase in grade of glioma and there exists a significant inverse relation between grade and GFAP expression.

\section{Summary and Conclusion}

Glial tumours are the most common primary tumours of brain with survival rate depending on the grade of tumour. Proper diagnosis plays a vital role because it is essential for the appropriate management of patient. Neurological examination, imaging and histopathological examination helps in diagnosis. Though histopathological analysis is gold standard. immunohistochemical studies aids in confirmation of diagnosis

Immunohistochemistry offers a powerful technique with its capacity to identify biologically important molecule. GFAP is reliable diagnostic marker whose staining allows appropriate diagnosis.

Expression of GFAP decreases with increase the grade of glial tumours. GFAP helps in differentiating different types of glial tumours on one hand and glial andnon-glial tumours on other hand. So GFAP status is necessary for confirmation of diagnosis and assessing the degree of tumour differentiation.

In present study 30 cases of glial tumours which includes both low grade and high grade tumours. Immunohistochemical staining of GFAP was evaluated. GFAP was positive in $87 \%$ cases. GFAP staining did not show any significant relation with age, sex and location of tumour.

In present study there was significant inverse correlation with grade of glioma with $\mathrm{p}$ value < 0.01(highly significant) and GFAP expression with low grade tumours showing intense GFAP staining and higher-grade tumour showing less expression. This concludes that GFAP expression decreases as the grade increases.

Thus, GFAP is reliable diagnostic marker helps in appropriate diagnosis whose expression is comparatively lost in higher grade tumours suggesting inverse correlation with the grade of glioma. 


\section{Acknowledgements}

To start with, I thank the almighty GOD in making this project a successful one.

I express my deep gratitude to Dr.Edwin Joe, Dean, Coimbatore Medical College, for granting me permission to undertake this study.

I profusely thank and express my sincere gratitude to Dr. C. Lalitha, M.D., Professor and Head, Department of Pathology, Coimbatore Medical College, for having suggested this topic for dissertation and for having rendered her valuable support and encouragement without which this project work would not have been feasible.

I am extremely grateful and my sincere thanks to Dr.A.Arjunan, M.D., Professor, for his invaluable suggestions, guidance, support and constant encouragement during this endurable work.

I also extend my thanks to Dr. A. Dhanalakshmi, M.D., Dr. G.S. Thiriveni Balajjii, M.D., of the Department of Pathology, Coimbatore Medical College, for their invaluable suggestions and encouragement throughout the work.

I also thank all my associate professors, Assistant Professors and Tutors for their support and guidance.

I extend my heartfelt thanks to all my collegues for their timely help, comments and support.

I thank all the technical staff in the Department of Pathology, Coimbatore Medical College, for their sincere and timely technical assistance.

Also, I express my heartfelt thanks to my husband Dr. S. Muthukumar for his constant support, encouraging words and source of strength all the way through this endeavour.

I express my gratitude to parents, my lovable sister and my in laws for their extreme patience and tireless support while pursuing this study.

Last but not the least, I profusely thank all the patients who had consented and kindly cooperated with me for the study.

Grants Obtained: None
Bibliography

1. Ohgaki H, Kleihues P (June 2005). "Population-based studies on incidence, survival rates, and genetic alterations in astrocytic and oligodendroglial gliomas". J Neuropathol Exp Neurol.64 (6): 479-89.

2. Verhaak RGW, Hoadley KA, Purdom E, et al: Integrated genomic analysis identifies clinically relevant subtypes of glioblastoma characterized by abnormalities in PDGFRA, IDH1, EGFR, and NF1. Cancer Cell 17:98-110, 2010.

3. Yan H, Parsons W, Jin G, McLendon R, et al: IDH1 and IDH2 mutations in gliomas. New Eng J Med 360:765-73, 2009.

4. James IW, Tim MH, David LN et al.: Diagnostic pathology of nervous system tumors. Churchill Livingstone Inc. 2002: 2-15.

5. Christian Rickert $\mathrm{H} \&$ Werner $\mathrm{P}$. Prognosis related histomorphological \& immunehistochemical markers in central nervous system tumors of childhood \& adolescence. Actaneuropathol. 2005:101109.

6. Tarik T, Tiannihou Z, Emi $\mathrm{H}$ et al.: The prognostic value of histological grading of posterior fossa ependymomas in children: a children's oncology group study \& a review of prognostic factors. Mod Pathol. 2008; 21: 165-177.

7. Jung TY \& Jung S. Early neuroimaging findings of glioblastoma mimicking nonneoplastic cerebral lesions. Neurol Med Chir (Tokyo). 2007; 47(9):424-427.

8. Donaldson SS, Laningham F, Fisher PG (2006). "Advances toward an understanding of brain stem gliomas". $J$ Clin Oncol24: 1266-12.

9. Louis DN, Ohgaki H, Wiestler OD, Cavenee WK. WHO Classification of Tumours of the Central Nervous System. Lyon: International Agency for Research; 2007. 
10. Burger PC, Scheithauer BW. American Registry of Pathology. Washington, DC: Armed Forces Institute of Pathology (U.S.): Tumors of the Central Nervous System. American Registry of Pathology in collaboration with the Armed Forces Institute of Pathology; 2007. 